*akls View/Frint Document Cover Sheet tow

This document was retrieved from the Boeing ISEARCH System.

Accession \#: D196071806

Document \#: SD-WM-ER-520

Title/Desc:

FERROCYANIDE SAFETY PROGRAM IN TANK APPLICATION OF ELECTROMAGNETIC INDUCTION MOISTURE MEASUREMENTS FY1995 REPORT 
$(t 6 / \angle 0) Z \angle 1-00 t \angle-08$

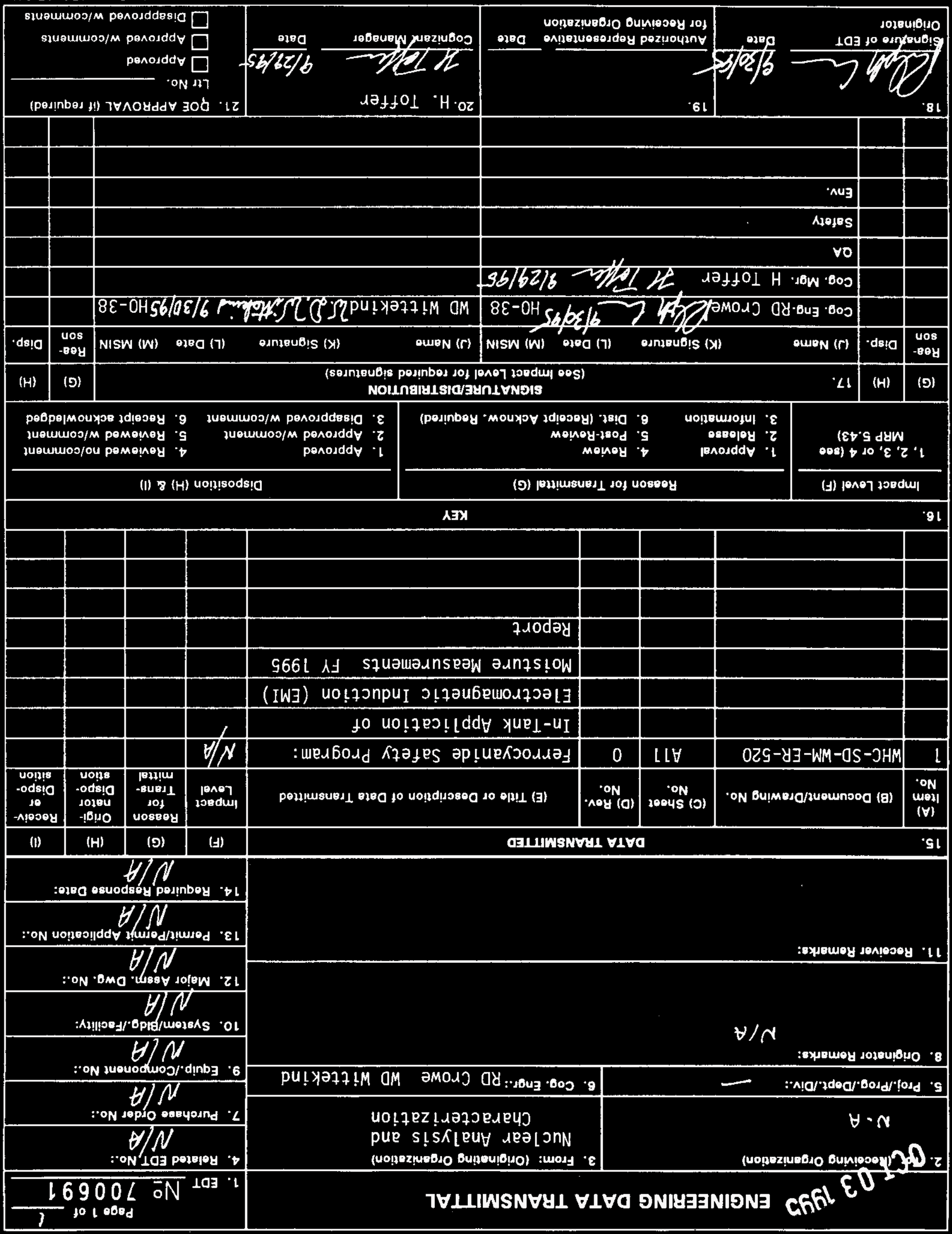




\section{RELEASE AUTHORIZATION}

Document Number: WHC-SD-WM-ER-520, REV 0

$\begin{array}{ll}\text { Ferrocyanide Safety Program: In-Tank App } \\ \text { Document Title: } & \text { Electromagnet ic Induction (EMI) Moisture }\end{array}$

Measurements FY 1995 Report

Release Date: $\quad 10 / 3 / 95$

This document was reviewed following the procedures described in WHC-CM-3-4 and is:

\section{APPROVED FOR PUBLIC RELEASE}

WHC Information Release Administration Specialist:
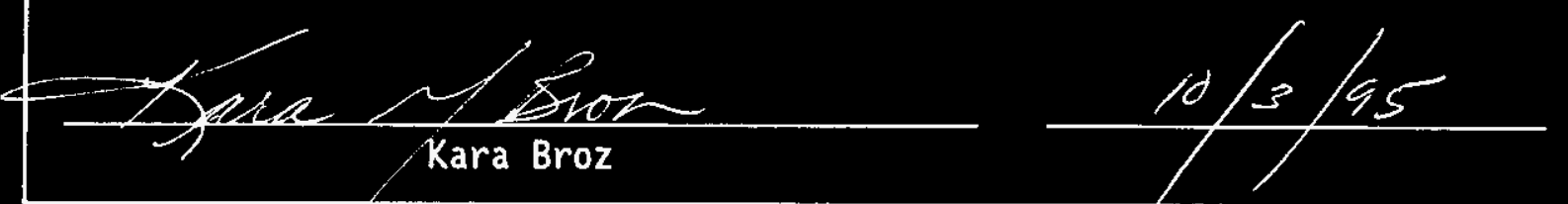

TRADEMARK DISCLAIMER. Reference herein to any specific commercial product, process, or service by trade name, trademark, manufacturer, or otherwise, does not necessarily constitute or imply its endorsement, recommendation, or favoring by the United States Government or any agency thereof or its contractors or subcontractors.

This report has been reproduced from the best available copy. Available in paper copy. Printed in the United States of America. To obtain copies of this report, contact:

West inghouse Hanford Company - Document Control Services

P.0. Box 1970, Mailstop H6-08, Richland, WA 99352

Telephone: (509) 372-2420; Fax: (509) 376-4989 


\section{SUPPORTING DOCUMENT}

1. Total Pages

2. Title

Ferrocyanide Safety Program: In-Tank Application of Electromagnetic Induction (EMI) Moisture Measurements FY 1995 Report

5. Key Hords

Probe, waste tanks, moisture measurements, EMI

3. Number

WHC-SD-WM-ER-520

4. Rev No.

0

6. Author

Name: R. D. Crowe

W. D. Wittekind

W augw D.2 Witheleind 9/30/95

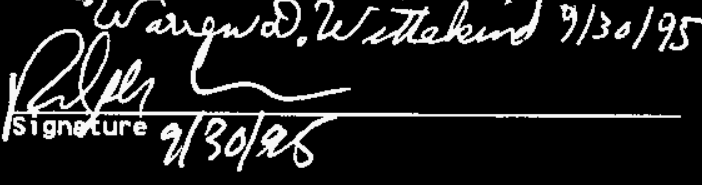

Organization/Charge Code

$8 M 720$ / N2C48

\section{Abstract}

This report provides a status of the engineering testing of the EMI technique for measurement of moisture levels in tank waste. EMI probes and the associated electronic equipment were designed, specified, procured, and tested to determine if the EMI technique could determine moisture in tank wastes. Work this year has confirmed that the technique will be useful for measurement of moisture in the waste tanks.

8.

RELEASE STAMP

OFFICIAL REELESE BY WHC DATE OCT 03 iNSO 


\title{
Ferrocyanide Safety Program: In-Tank Application of Electromagnetic Induction (EMI) Moisture Measurements FY 1995 Report
}

\author{
R. D. Crowe \\ W. D. Wittekind
}

Date Published

September 1995

Prepared for the U.S. Department of Energy

Assistant Secretary for Environmental Management

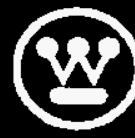

Westinghouse

P.O Box 1970

Hanford Company Richland, Washington

Management and Operations Contractor for the

U.S. Department of Energy under Contract DE-AC06-87RL10930

Copyright Licenes By acceptence of this article, the publisher and/or recipient acknowledges the

U.S. Government's right to retain a nonexclusive, royahty-free license in and to any copyright covering this paper.

Approved for public release; distribution is unlimited 


\section{CONTENTS}

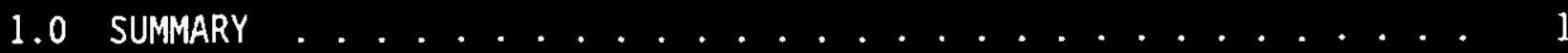

2.0 THEORY OF ELECTROMAGNETIC INDUCTION MOISTURE MEASUREMENT . . . . . 2

2.1 ELECTROMAGNETIC INDUCTION MEASUREMENT OF ELECTRICAL

CONDUCTIVITY ....................... 2

2.2 ELECTRICAL CONDUCTIVITY DEPENDENCE ON MOISTURE CONTENT . . . 2

2.2.1 Electrical Conductivity of Electrolytic Solutions . . 5

2.2.2 Electrical Conductivity Measurements and Solution 1.5

2.2.3 Electrical Conductivity of Solution in a Porous Solid Matrix ............. 8

3.0 COMPUTER MODELING CALCULATIONS . . . . . . . . . . 12

4.0 ELECTROMAGNETIC INDUCTION HAROWARE DESCRIPTION ....... 13

4.1 ELECTROMAGNETIC INDUCTION PROBES FOR LOW APPLICATIONS .... 13

4.2 MIZ-4OA EDDY CURRENT TESTER . . . . . . . . . . . 15

4.3 3D PROBE PUSHER-PULLER FOR LOW DEPLOYMENT ........ 15

4.4 ELECTROMAGNETIC INDUCTION ELECTRICAL CONDUCTIVITY TEST

STANDS ................. 16

5.0 ELECTROMAGNETIC INDUCTION IN-TANK MEASUREMENTS . . . . . . 16

5.1 ELECTROMAGNETIC INDUCTION SCANS IN HIGH-LEVEL WASTE TANKS * 16

5.1.1 Resolution and Repeatability ........... 18

5.1.2 Interrogation Depth .......... 19

5.2 ELECTROMAGNETIC INDUCTION SCANS COMPARED TO NEUTRON AND GAMMA

SCANS . . . . . . . . . . . . . . 26

5.3 ELECTROMAGNETIC INDUCTION SCAN CALIBRATION RESULTS . . . . 32

6.0 AREAS OF FUTURE WORK . . . . . . . . . . . . 32

7.0 CONCLUSIONS ................... 35

8.0 REFERENCES ........................... 36 


\section{LIST OF FIGURES}

Figure 2.1 Electromagnetic Induction Moisture Probe for LOWs ...... . 3

Figure 2.2 Electrical Conductivity Between Pure Water and Fused Salt . . . 4

Figure 2.3 Electrical Conductivity of Chemical Solutions Lab Setup . . . . 6

Figure 2.4 Electrical Conductivity versus Liquid Volume ......... 10

Figure 4.1 Electromagnetic Induction System ........... 14

Figure 4.2 Electromagnetic Induction Laboratory Test Stands . . . . . . . 17

Figure 5.1 Repeatability of Amplitude Measurement for 241-BY-104 . . . . 19

Figure 5.2 Repeatability of Phase Measurement for 241-BY-104 . . . . . 20

Figure 5.3 Scan Amplitude at Lower Frequencies . . . . . . . . . . . 22

Figure 5.4 Scan Phase at Lower Frequencies ... . . . . . . . . . . 23

Figure 5.5 Scan Amplitude at Higher Frequencies .......... 24

Figure 5.6 Scan Phase at Higher Frequencies ....... . . . . . 25

Figure 5.7 Scan Amplitude at Different Coil Spacings . . . . . . . . . 27

Figure 5.8 Scan Phase at Different Coil Spacings . . . . . . . . . 28

Figure 5.9 Electromagnetic Induction Probe and Neutron Probe Scans . . . 29

Figure 5.10 Electromagnetic Induction Probe and Gamma Probe Scans . . . 30

Figure 5.11 Waste Surface inside Tank 241-BY-104 . . . . . . . . . . 31

Figure 5.12 Calibration Measurements ......... 33

Figure 5.13 Estimated Electrical Conductivity for Tank 241-BY-104 . . . 34

\section{LIST OF TABLES}

Table 2.1 Predicted Electrical Conductivity of Analyzed Compositions . . 7

Table 2.2 Parameters to Calculate Electrical Conductivity . . . . . . 9

Table 2.3 Archie's Law Electrical Conductivity........... II

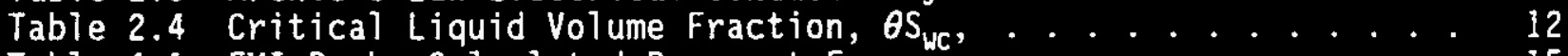

Table 4.1 EMI Probe Ca1culated Resonant Frequency . . . . . . . . I5

Table 5.1 Single-Shell Tank Scans ............ 18 


\subsection{SUNMARY}

This report provides a summary of the electromagnetic induction (EMI) work in progress, describes the underlying theory for in-tank application, and success to date. This work represents results of the application of the EMI probe to actual in-tank measurements and expands on EM-50 work begun by Battelle Pacific Northwest Laboratories (PNL).

An EMI system to infer moisture content in Hanford Site high-level waste (HLW) tanks by measuring the electrical conductivity has been assembled and tested in the laboratory. In-tank measurements in liquid observation wells (LOW) have been made in several single-shell tanks of interest to the ferrocyanide safety program. The basis for converting electrical conductivity to moisture content was developed from Archie's Law (de Witte 1953). This equation has been used in the geophysics community since the 1940 's to relate electrical conductivity in porous media with the electrolyte conductivity, porous volume and liquid volume fraction (Doll 1949, Moran and Kunz 1962, Wait 1971, and Serra 1984).

In-tank EMI measurements were performed at frequencies between $50 \mathrm{kHz}$ and $2.0 \mathrm{MHz}$, with driver/receiver coil spacings of $1.5 \mathrm{in.,} 3 \mathrm{in.,} 6 \mathrm{in}$, and 12 in. Repeatability of EMI measurements were demonstrated by comparing measurements recorded from different scans. The EMI results are shown to correlate with gamma scans and active neutron scans. Different in-tank features were apparent from the different frequencies.

EMI calibration standards were designed, built, and measured to provide an EMI signal to known electrical conductivity calibration.

The characteristics of the EMI probe are the following:

- Good vertical spatial resolution,

- Good radial spatial resolution with multiple depth interrogations,

- Ability to look through adjacent regions to deeper regions,

- Sensitive to small changes in material properties,

- Electrical conductivity goes to zero at 8 to $12 \%$ volume fraction of 7 iquid, and

- Light weight probes with low voltage requirements.

The following areas have been identified as requiring additional work.

- Analytic calculations of EMI response for EMI probes in known geometries for better electrical conductivity interpretation,

- Routine temperature effect compensation for solution electrical conductivity temperature dependence, and

- Further development of EMI electrical conductivity measurements to volume and weight fraction moisture content. 


\subsection{THEORY OF ELECTROMAGNETIC INDUCTION MOISTURE MEASUREMENT}

The theory of EMI moisture measurement will be discussed in two sections: (1) EMI measurement of electrical conductivity, and (2) electrical conductivity dependance on moisture content.

\subsection{ELECTRONAGNETIC INDUCTION MEASUREMENT OF ELECTRICAL CONDUCTIVITY}

The EMI measurement of electrical conductivity depends on an alternating current energizing a driver coil. A magnetic field and corresponding electrical field are produced from the current flowing in the driver coil. These fields induce a current in the receiver coil as well as secondary currents in the surrounding conductive waste material that are $90^{\circ}$ out of phase with the driving coil current (Figure 2.1). The secondary currents in the adjacent conductive medium in turn induce a current in the receiver coil that is $180^{\circ}$ out of phase with the original driving coil current.

Two voltage signals are created at the receiver coil: the $90^{\circ}$ out of phase signal direct from the driving coil and the $180^{\circ}$ out of phase indirect signal generated from the electrical conductivity of the adjacent medium. A phase sensitive impedance meter can separate these two signal components and determine the magnitude of the signal coming from the electrical conductivity of the surrounding medium.

\subsection{ELECTRICAL CONDUCTIVITY DEPENDENCE ON MOISTURE CONTENT}

The EMI technique measures electrical conductivity, so it is important to develop a theoretical basis for describing the electrical conductivity of the waste in the tanks. This description will be performed in two parts; first, the electrical conductivity of the electrolyte solution (interstitial liquid, or supernatant or drainable liquid), and second, the electrical conductivity of the electrolyte solution in a porous solid matrix.

The electrical conductivity of aqueous solutions ranging between pure water and fused solid salt can be described in terms of four regions with the following five boundary conditions:

1. Pure water,

2. Chemically saturated electrolytic solution,

3. Wet solid with all porous volume filled with liquid,

4. Moist solid dried to the loss of hydraulic conductivity, and

5. Completely dry fused solid.

The behavior of electrical conductivity for conditions from pure water to fused salt are depicted in Figure 2.2. At both extremes on the figure, pure water and very dry salt, the electrical conductivity is very low. Between these two extremes, there exists a maximum in the electrical conductivity. 
Figure 2.1. Electromagnetic Induction Moisture Probe for LOWs.

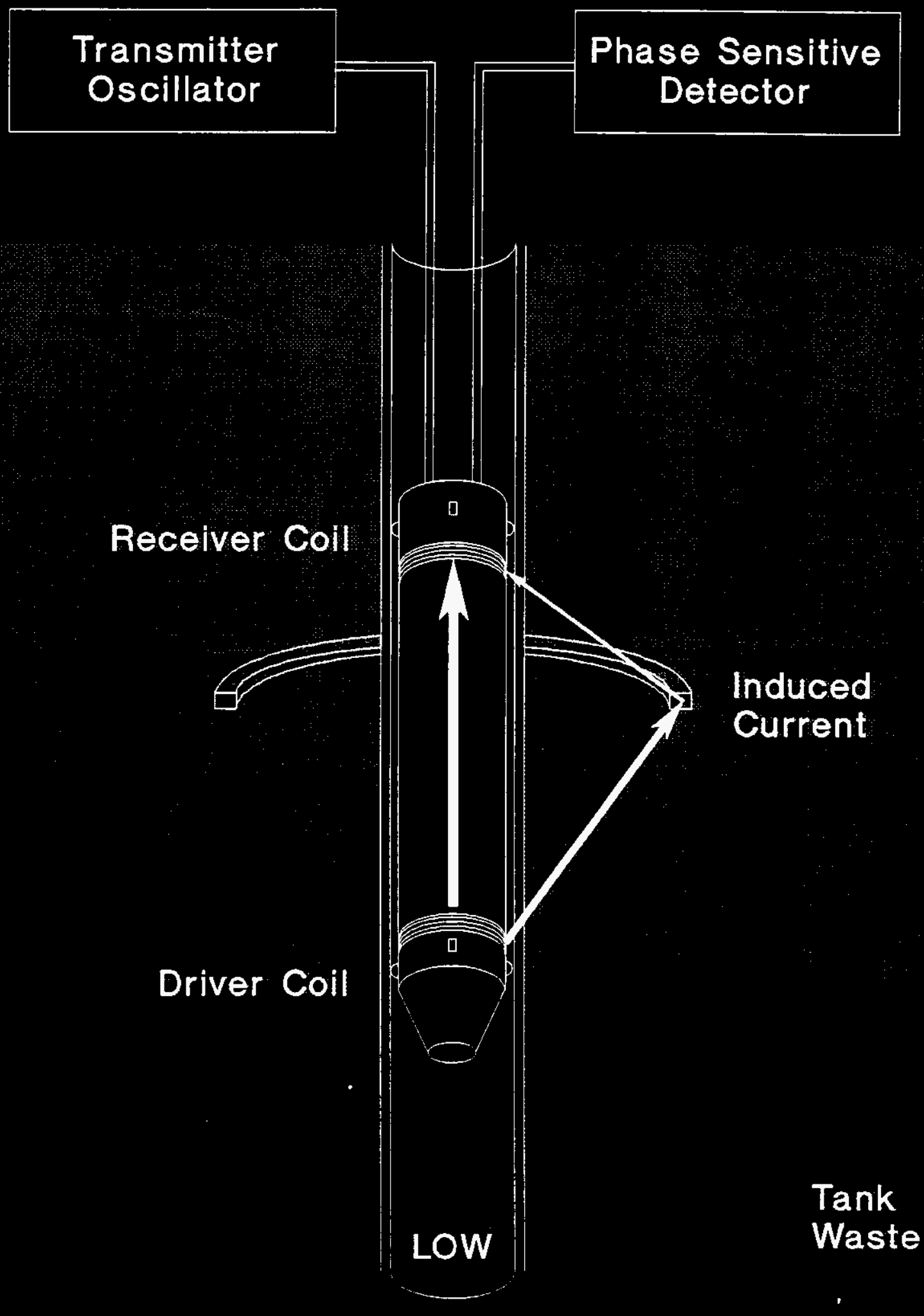


Figure 2.2. Electrical Conductivity Between Pure Water and Fused Salt.

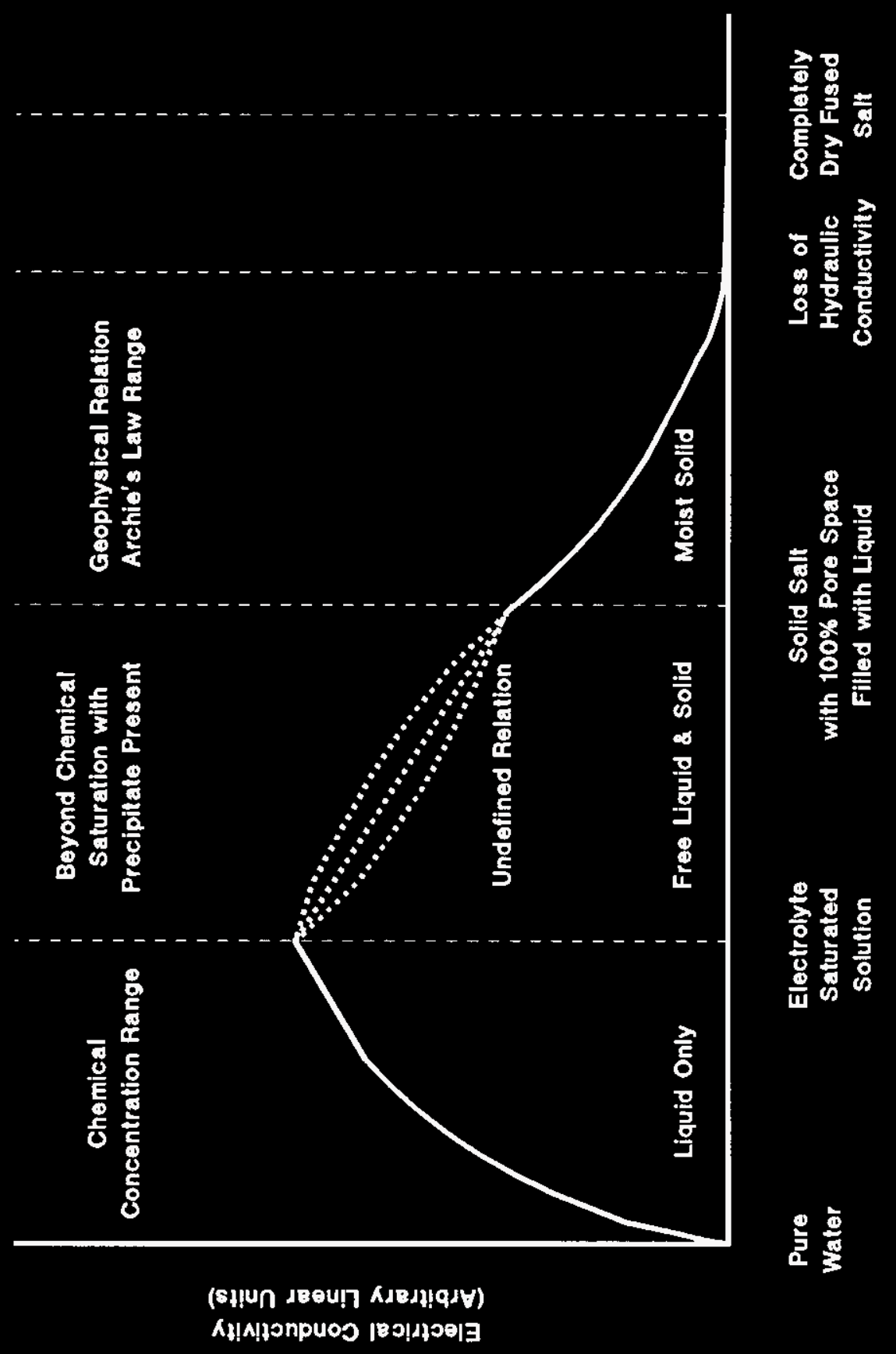


The electrical conductivity increases as electrolytes are added into solution, but the rate of increase begins to diminish as the concentration approaches saturation. At electrolyte saturation, the electrical conductivity is at the maximum. As more electrolytes are added to the mixture, the proportion of solids to liquid increases until the electrolyte solution exists only as interstitial liquid. The relationship of electrical conductivity and concentration is undefined in this region.

As water is removed from the pore spaces of the fused sait, the electrical conductivity decreases according to Archie's Law, as known to the geophysics community since the mid $1940^{\prime} \mathrm{s}$. As more liquid is lost, the electrical conductivity decreases until hydraulic conductivity is lost, (the pore volumes are no longer connected by liquid) and the electrical conductivity drops to near zero.

The two regions of most interest are the electrical conductivity of unsaturated electrolytic solutions, and saturated electrolytic solutions in a porous solid matrix. These two situations are discussed in separate sections.

\subsubsection{Electrical Conductivity of Electrolytic Solutions}

The electrical conductivity of a solution depends on the number of the dissociated jons in the solution, and their mobility and the electrical charges of each of the ions. The number of dissociated ions depends on the solubility of various constituent salts. The larger the number of dissociated ions, the higher the absolute electrical conductivity. However, the specific conductance, electrical conductivity per ion, decreases steadily with the increase in the number of ions.

For most ions, the ionic mobility or conductivity per electrical charge in aqueous solution is remarkabiy similar, within approximately a factor of 2 . There are two notable exceptions, $\mathrm{H}^{+}$and $\mathrm{OH}^{-}$. The ionic conductivity to $\mathrm{H}^{+}$is about 7 times and $\mathrm{OH}^{-}$is about 4 times greater than for most ions. The waste tanks are maintained basic, so the $\mathrm{H}^{+}$is absent and only the $\mathrm{OH}^{-}$contribution needs to be considered.

The dominant waste constituents in the tanks are $\mathrm{NaNO}_{3}, \mathrm{NaNO}_{2}, \mathrm{NaOH}$, and $\mathrm{NaAlO}_{2}$ (Barney 1976, Reynolds and Herting 1984). The chemical proportion varies between waste types. Supernatant may or may not be saturated with electrolytic salts, but the interstitial liquid in the pore spaces of fused salts is considered to be a saturated solution. A review of the sample data for the single-shell waste tanks led to the design of a series of conductivity measurements to characterize the electrical conductivity of the waste.

\subsubsection{Electrical Conductivity Measurements and Solution Modeling}

Twenty seven different solution combinations of $\mathrm{NaOH}, \mathrm{NaAlO}, \mathrm{NaNO}_{3}$, and $\mathrm{NaNO}_{2}$ were measured for conductivity. The experimental setup is depicted in Figure 2.3. A conductivity probe was inserted into each test sample container, the container sealed and placed in a hot water bath. Sealing the container prevented evaporation that would change the solution conductivity. 
Figure 2.3. Electrical Conductivity of Chemical Solutions Lab Setup.

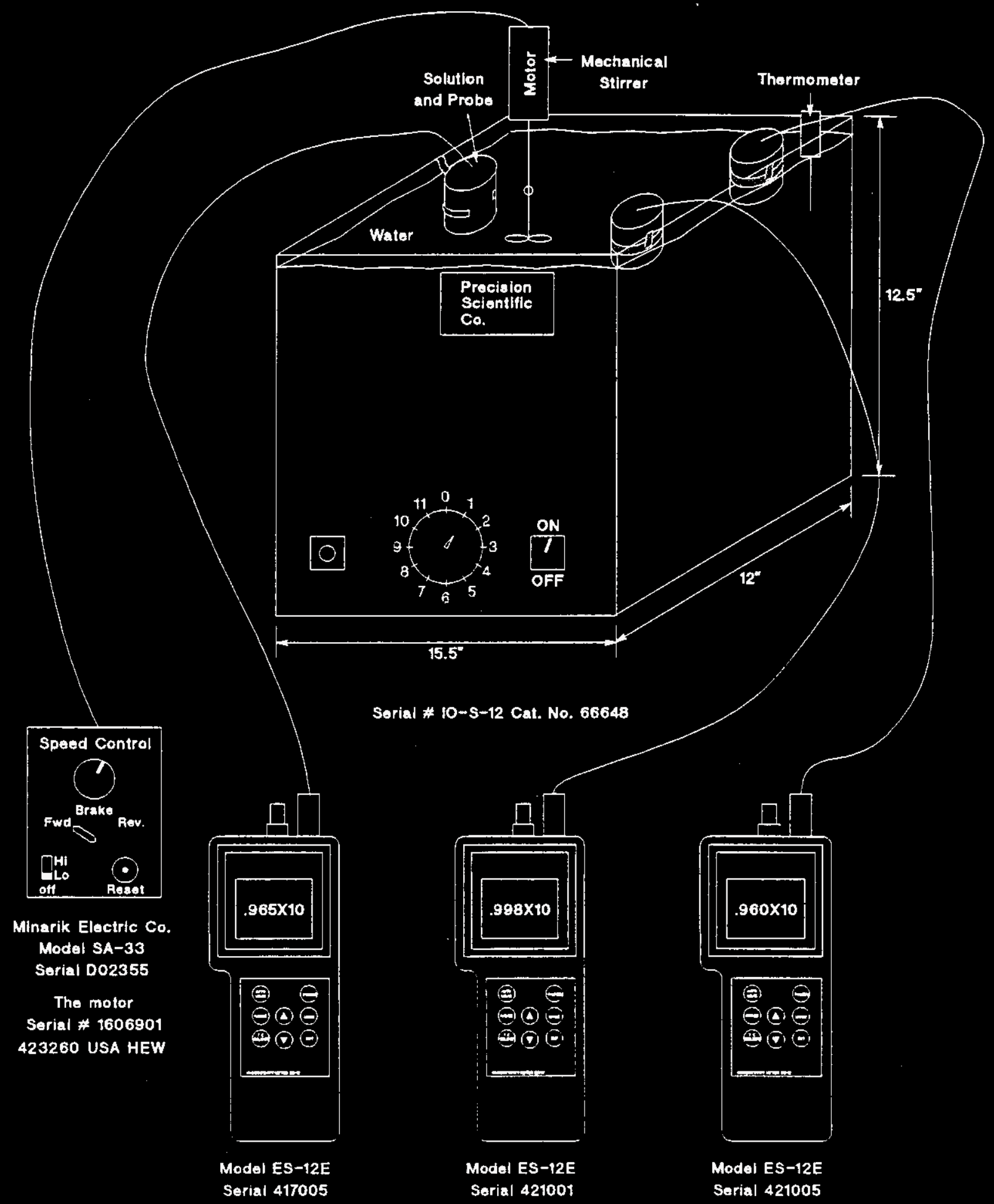


The hot water bath was then heated slowly from room temperature to $80{ }^{\circ} \mathrm{C}$. Conductivity measurements were recorded at regular temperature intervals. These values were used in a statistical regression to generate fitted empirical coefficients. This allowed estimation of the electrical conductivity for solutions identified in the chemical analyses of single-shell waste liquid samples.

There were two experimental tests designed: (1) a four component $\left(\mathrm{NaNO}_{3}, \mathrm{NaNO}_{2}, \mathrm{NaOH}\right.$, and $\mathrm{NaAlO}_{2}$ ), three level series with 27 test solutions to cover the range of $2 \mathrm{M}$ to $6 \mathrm{M} \mathrm{NaOH}$, and (2) a three component $\left(\mathrm{NaNO}_{3}, \mathrm{NaNO}_{2}\right.$, and $\mathrm{NaOH}$ ), three level series with 15 test solutions to cover the range of oM to $2 \mathrm{M} \mathrm{NaOH}$. These two series encompass the major components of expected interstitial liquids and supernatant solutions in the waste tanks. Two series of experimental tests were necessary because the $\mathrm{NaAlO}_{2}$ is only soluble in the range of $2 \mathrm{M}$ to $6 \mathrm{M} \mathrm{NaOH}$. The temperature in the hot water baths varied between approximately $20^{\circ} \mathrm{C}$ and $80^{\circ} \mathrm{C}$, allowing the temperature-dependent electrical conductivity to be determined as a function of chemical composition.

The electrical conductivity of the chemical composition test series was, at specific temperatures, modeled using a statistics program. The electrical conductivity in $\mathrm{mS} / \mathrm{cm}$ was the dependent variable. The independent variables were the molarity of the $\mathrm{NaOH}, \mathrm{NaNO}_{3}, \mathrm{NaNO}_{2}$, and $\mathrm{NaAlO}_{2}$. Terms to second order were considered for their statistical significance with the less significant terms dropped. These fitted parameters were used to predict the electrical conductivity of the analyzed chemical compositions of the singleshe11 waste tanks.

A total of 72 drainable liquid or supernatant solution chemical analyses were reported (Van Vleet 1993). These form the database of expected compositions for interstitial 1 iquid and were used to define the experimental range of constituents. Not all the samples had sufficient data to estimate the electrical conductivity. Eighteen of the 72 were 1 isted as drainable liquids, while the other 54 were listed as supernatant solutions. The results are shown in the Table 2.1. The boxes with only two observations are not considered statistically significant, six observations are required to be statistically significant.

Table 2.1. Predicted Electrical Conductivity of Analyzed Compositions.

\begin{tabular}{||c|c|c|c|}
\hline Liquid, OH $(M)$ & $25{ }^{\circ} \mathrm{C}$ & $50{ }^{\circ} \mathrm{C}$ & $75{ }^{\circ} \mathrm{C}$ \\
\hline $\begin{array}{l}\text { Drainable }<2 M \\
(6 \text { samples) }\end{array}$ & $182.6 \pm 45.5$ & $273.5 \pm 71.1$ & $384.4 \pm 96.3$ \\
\hline $\begin{array}{l}\text { Supernatant < 2M } \\
(22 \text { samples) }\end{array}$ & $186.4 \pm 48.9$ & $279.4 \pm 75.9$ & $372.5 \pm 102.7$ \\
\hline $\begin{array}{l}\text { Drainable 2-6M } \\
(2 \text { samples) }\end{array}$ & $180.6 \pm 8.9$ & $312.9 \pm 14.3$ & $442.0 \pm 13.6$ \\
\hline $\begin{array}{l}\text { Supernatant 2-6M } \\
(9 \text { samples) }\end{array}$ & $160.7 \pm 51.7$ & $296.8 \pm 65.4$ & $422.2 \pm 87.3$ \\
\hline
\end{tabular}



from:

These results demonstrate that the EMI data interpretation would benefit

- knowing the temperature distribution of the waste tank being scanned, and

- knowing the approximate chemical composition of the tank waste being scanned.

The most important of these two quantities is the waste temperature, which is also the easiest one to measure. A completely unknown chemical composition could introduce an uncertainty on the order of approximately $25 \%$ relative to one standard deviation. Of course, any additional tank specific facts and information could reduce the uncertainty in the electrical conductivity. It should be noted that the electrical conductivity behavior of going to near zero as the hydraulic conductivity is lost is not affected by the uncertainty of unknown chemical composition.

\subsubsection{Electrical Conductivity of Solution in a Porous Solid Matrix}

The electrical conductivity of an electrolytic solution in a solid matrix has been the subject of geophysical investigation related to electrolytes in rock matrices. Porous rock is considered a three-dimensional volume filled with pore reservoirs within a solid matrix. The pores are connected through interconnecting channels. The sum of the volume due to the pore and interconnecting channels is the porosity. The electrical conductivity is due to the existence of the channels between the pores. Losing liquid from the pore reservoirs decreases the electrical conductivity, but losing liquid from the channel regions produces a much greater decrease.

The relationship between the electrical resistivity of the interstitial liquid and the electrical resistivity of the solid-liquid matrix is known as "Archie's Law."

$$
\rho_{t}=a \rho_{w} \theta^{-m}
$$

where $\rho_{t}$ is the bulk resistivity of the rock/liquid matrix, $\rho_{H}$ is the resistivity of the electrolytic liquid which is in the porous volume, $\theta$ is the porosity expressed as a fraction per unit volume of the solid matrix, and a and $\mathrm{m}$ are empirical parameters. Sedimentary rocks, believed to be most representative of the waste, have reasonably consistent values of a and $m$ (de Witte 1953). The effect of the loss of liquids resulting in the partial filling of the pore spaces depends on the proportion of the filled pore spaces remaining. There is a critical ratio, $S_{w c}$, of liquid to pore space that defines the effect. Above the critical values for $S_{M C}$, the behavior is given by equation (2).

$$
\rho_{t}=a \rho_{w} \theta^{-m}\left(S_{w}\right)^{-n_{1}} \quad\left(S_{w c} \leq S_{w} \leq 1\right)
$$

where $S_{w}$ is the volume fraction of porous volume occupied by liquid, $n_{1}$ is an exponent that is usually about 2 .

The relation for $S_{W}$ less than some critical liquid to available pore space proportion, $S_{w c}$, is shown in equation 3 . 
WHC-SD-WM-ER-520 Rev 0

$$
\rho_{t}=a \rho_{w} \theta^{-m} b\left(S_{w}\right)^{-n_{2}} \quad\left(0 \leq S_{w} \leq S_{w c}\right)
$$

where $S_{w}$ is the volume fraction of porous volume occupied by liquid, $b$ is a parameter about 0.05 for sedimentary rocks, and $n_{2}$ is an exponent usually between 4 and 5 . The most significant feature of the partial liquid filling of the porous volume of solids is that below a critical liquid volume fraction the electrical conductivity decreases very rapidly. The pore spaces must be interconnected and filled with liquid in order for the rocks to conduct electricity.

Because the EMI measurements are more easily understood in terms of electrical conductivity, these equations are converted to $\sigma_{t}$, the electrical conductivity of the rock/liquid matrix.

$$
\begin{array}{cr}
\sigma_{t}\left(\theta S_{w}\right)=a^{-1} \sigma_{w} \theta^{m} & \left(S_{w}=1\right) \\
\sigma_{t}\left(\theta S_{w}\right)=a^{-1} \sigma_{w} \theta^{m}\left(S_{w}\right)^{n_{1}} & \left(S_{w c} \leq S_{w} \leq 1\right) \\
\sigma_{t}\left(\theta S_{w}\right)=a^{-1} \sigma_{w} \theta^{m} b^{-1}\left(S_{w}\right)^{n_{2}} & \left(0 \leq S_{w} \leq S_{w c}\right)
\end{array}
$$

where $\sigma_{t}$ is the bulk conductivity of the rock/liquid matrix, $\theta S_{w}$ is the liquid volume fraction, $\sigma_{w}$ is the conductivity of the electrolytic liquid in the porous volume, $\theta$ is the porosity expressed as a fraction per unit volume of

\begin{tabular}{|c|c|c|}
\hline \multicolumn{3}{|c|}{$\begin{array}{l}\text { Table } 2.2 \text { Parameters to Calculate Electrical Conductivity } \\
\text { As a Function of Liquid Volume Fraction } \\
\text { In a Porous Medium using Archie's Law }\end{array}$} \\
\hline & Porous Medium & dimensions \\
\hline$\sigma_{u}$ & 200 & $\mathrm{mS} / \mathrm{cm}$ \\
\hline$\rho_{\mu}$ & 0.05 & $0 h m^{-1} m^{-1}$ \\
\hline$\theta$ min & 0.4 & Porosity minimum \\
\hline$\theta \max$ & 0.8 & Porosity maximum \\
\hline a & 0.88 & \\
\hline m & -1.37 & \\
\hline$S_{\text {inc }}$ & 0.25 & Critical Liquid Volume Fraction \\
\hline$n 1$ & -2 & \\
\hline b & 0.03125 & $\left(S_{M c}\right)^{N 1}=b\left(S_{M C}\right)^{N 2}$ \\
\hline n2 & -4.5 & \\
\hline
\end{tabular}
the solid matrix, and $a, m, n_{1}, b$, and $n_{2}$ are empirical parameters.

Table 2.2 lists the values used in the calculations for Figure 2.4. The calculated values are included in Table 2.3 . 
Figure 2.4. Electrical Conductivity versus Liquid Volume.
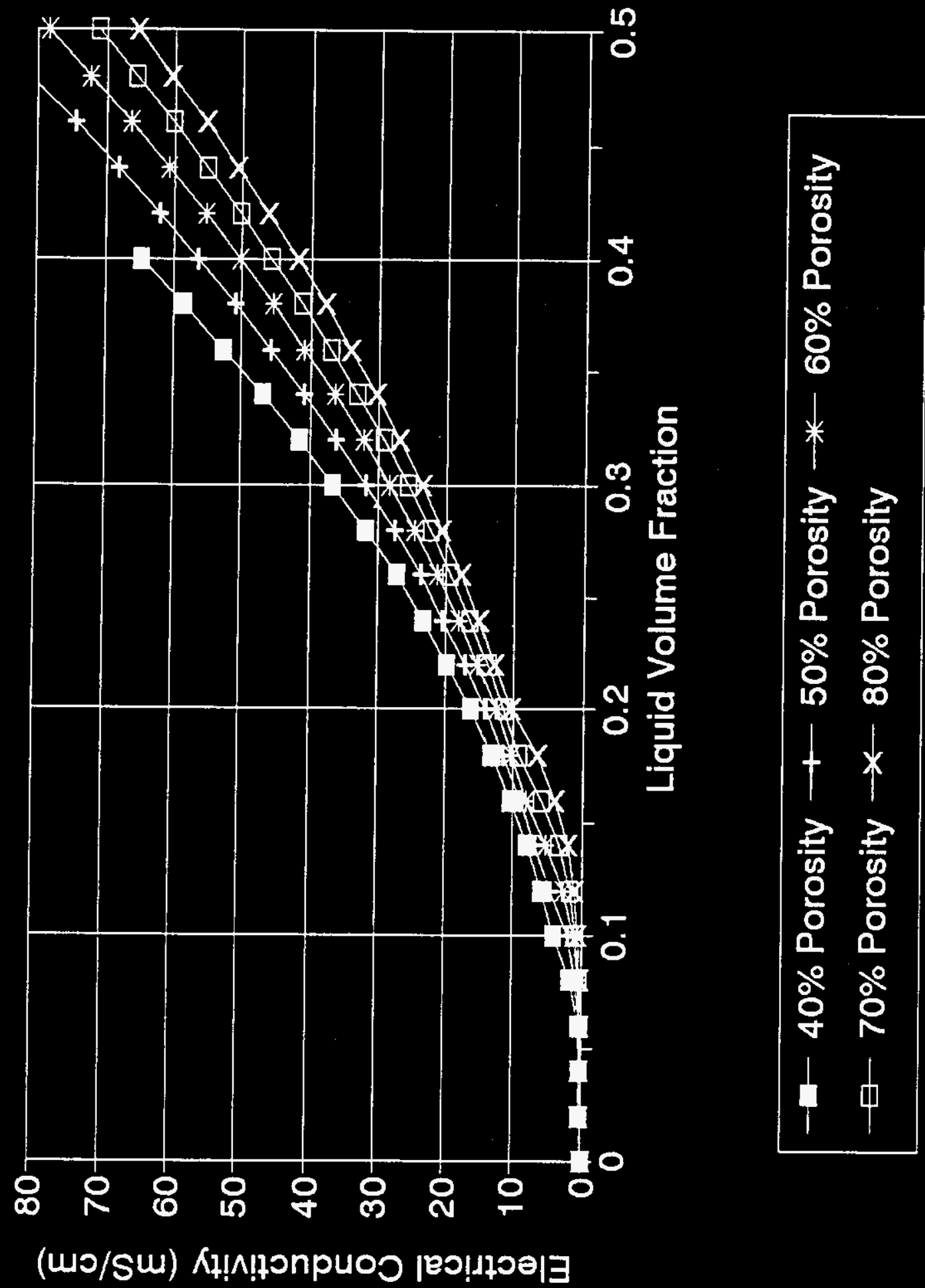


\begin{tabular}{|c|c|c|c|c|c|}
\hline$\overline{0}$ & $\overline{0}$ & $\overline{0}$ & 0 & 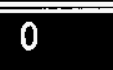 & $00^{\circ} 0$ \\
\hline 0.0 & 0.0 & 0.0 & 0.0 & 0.0 & 20.0 \\
\hline 0.0 & 0.0 & 0.0 & 0.0 & $\Gamma^{\circ} 0$ & $70^{\circ} 0$ \\
\hline 0.0 & $I^{\prime} 0$ & {$[.0$} & 2.0 & 6.0 & $90^{\circ} 0$ \\
\hline 2.0 & $\varepsilon^{\circ} 0$ & $t^{\circ} 0$ & $L^{\circ} 0$ & $g^{\circ} \mathrm{I}$ & $80^{\circ} 0$ \\
\hline 9.0 & $L^{\circ} 0$ & $I^{\circ} \mathrm{I}$ & 0.2 & 0.7 & $0 I^{\circ} 0$ \\
\hline$I^{\prime} I$ & $9^{\circ} \mathrm{I}$ & 9.2 & $9^{\circ} 6$ & 8.9 & $2 I^{\circ} 0$ \\
\hline$I^{\prime} \mathrm{z}$ & $\tau^{\prime} \varepsilon$ & $2 \cdot \mathrm{s}$ & 6.9 & $66^{\circ} \mathrm{L}$ & $t I^{\circ} 0$ \\
\hline $8^{\circ} \varepsilon$ & $8^{\circ} \mathrm{G}$ & 0.8 & 0.6 & $6^{\circ} \mathrm{OI}$ & $91^{\circ} 0$ \\
\hline 9.9 & $2^{\circ} 6$ & $2 \cdot 0 \mathrm{I}$ & $b^{\circ}$ II & $\mathrm{I}^{\circ} \boldsymbol{\varepsilon} \mathrm{I}$ & $8 \mathrm{I}^{\circ} 0$ \\
\hline S.0I & $b^{\circ}$ II & $\bar{G} 2 I$ & $I^{\circ} \rightarrow I$ & $2 \cdot 9[$ & $02^{\circ} 0$ \\
\hline$L^{\prime} \mathrm{ZI}$ & $8: \varepsilon I$ & Z.SI & $0^{\circ} \angle I$ & $9.6 \mathrm{I}$ & $22^{\circ} 0$ \\
\hline$I^{\prime}$ 'SI & $b^{\circ} 9 I$ & I'8I & $\varepsilon^{\circ} 02$ & $\varepsilon^{\prime} \varepsilon z$ & $62^{\circ} 0$ \\
\hline$L^{\circ} \angle I$ & $z^{\circ} 6 \mathrm{I}$ & $2 \cdot 12$ & $8^{\prime} \varepsilon Z$ & $b^{\circ} \angle 2$ & $92^{\circ} 0$ \\
\hline 9.02 & $\varepsilon^{\prime} z 2$ & $9^{\circ}+2$ & $9^{\circ} \angle 2$ & $L^{\circ} I \varepsilon$ & 82.0 \\
\hline $\mathrm{G}^{\cdot} \varepsilon z$ & $9^{\circ} 92$ & $2 \cdot 82$ & $L^{\prime} I \varepsilon$ & $t^{\circ} 9 \varepsilon$ & $0 \varepsilon^{\circ} 0$ \\
\hline 8.92 & $I^{\circ} 62$ & $I^{\prime} 2 \varepsilon$ & $0.9 \varepsilon$ & $\mathrm{g}^{\circ}$ Ib & $2 \varepsilon^{\circ} 0$ \\
\hline$\tau^{\prime} \cdot 0 \varepsilon$ & $6^{\circ} 2 \varepsilon$ & $2 \cdot 9 \varepsilon$ & $L^{\circ} 0 t$ & 8.96 & $b \varepsilon^{\circ} 0$ \\
\hline $6^{\circ} \varepsilon \varepsilon$ & $6.9 \varepsilon$ & $9^{\circ} 0 b$ & $9^{\circ} \mathrm{Sb}^{\prime}$ & S.ZS $^{\circ}$ & $9 \varepsilon^{\circ} 0$ \\
\hline $8^{\circ} L \varepsilon$ & $I^{\prime} \cdot \mathrm{Ib}$ & $\varepsilon^{\cdot} g_{t}$ & 8.09 & $9^{\circ} 89$ & $8 \varepsilon^{\circ} 0$ \\
\hline 6.16 & $\mathcal{S}^{\circ} \mathrm{Sb}$ & 2.09 & $\varepsilon^{\circ} 9 G$ & $8^{\circ}+9$ & $0 b^{\circ} 0$ \\
\hline$I^{\prime} 9 b$ & 2.09 & $\varepsilon^{\prime} \mathcal{G S}$ & 0.29 & & $2 t^{\circ} 0$ \\
\hline $9^{\circ} 0 \mathrm{~S}$ & I'SS & $L^{\circ} 09$ & $I^{1} 89$ & & $6 t^{\circ} 0$ \\
\hline$\varepsilon^{\prime} \mathcal{G S}$ & $2 \cdot 09$ & $\varepsilon^{\circ} 99$ & $b^{\circ}+L$ & & $9 b^{\circ} 0$ \\
\hline$\varepsilon^{\circ} 09$ & 9.59 & $2 \cdot 2 L$ & $0^{\circ} 18$ & & $86^{\circ} 0$ \\
\hline 6.59 & $I^{\prime} I L$ & $6.8 L$ & $6^{\circ} \angle 8$ & & $0 S^{\circ} 0$ \\
\hline 8.0 & $L^{\circ} 0$ & 9.0 & $\mathrm{~s}^{\circ} 0$ & $t \cdot 0$ & $\begin{array}{r}\text { uo!fJeds } \\
\text { aun }[0 \Lambda \text { p!nb!7 }\end{array}$ \\
\hline \multicolumn{6}{|c|}{ 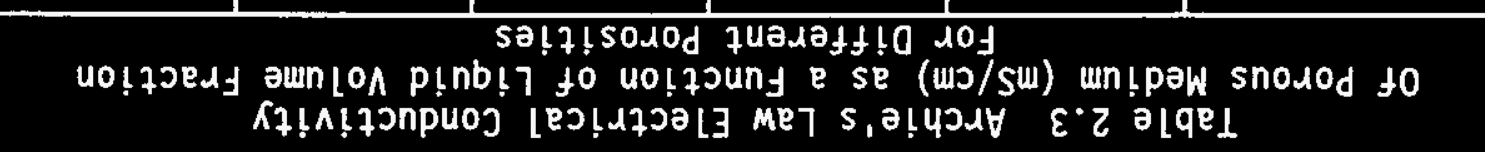 } \\
\hline
\end{tabular}


The critical liquid volume fraction, $S_{\text {uc }}$, depends on porosity as depicted in Table 2.4. The significance of this critical liquid volume, $S_{U C}$, is that the electrical conductivity of the moist solid decreases very sharply with further decreases in liquid volume fraction.

\begin{tabular}{|c|c|c|c|c|c|}
\hline $\begin{array}{rr}\text { Table } 2.4 \\
\text { Dep }\end{array}$ & $\begin{array}{l}\text { ritic } \\
\text { lance }\end{array}$ & $\begin{array}{l}\text { Liquid } \\
\text { Porous } \\
\end{array}$ & $\begin{array}{l}\text { ume } \mathrm{Fr} \\
\text { ium } \mathrm{Po} \\
\end{array}$ & $\begin{array}{l}\text { ion, } \theta \\
\text { ity }\end{array}$ & \\
\hline $\boldsymbol{\theta}$, Porosity & 0.4 & 0.5 & 0.6 & 0.7 & 0.8 \\
\hline $\begin{array}{l}S_{\text {Hc }}, \text { Critical } \\
\text { Liquid Proportion }\end{array}$ & 0.25 & 0.25 & 0.25 & 0.25 & 0.25 \\
\hline $\begin{array}{l}\theta S_{\text {uc }} \text { Critical } \\
\text { Liquid Volume }\end{array}$ & 0.100 & 0.125 & 0.150 & 0.175 & 0.200 \\
\hline
\end{tabular}

Because the porosity of single-shell tank contents must be estimated, an additional uncertainty arises in the liquid volume fraction calculations. The liquid volume fraction is the quantity $\theta S_{w}$. The water volume fraction could be calculated if an additional quantity is known, that is the water volume to liquid volume ratio. To infer the water weight percent, the additional quantities that would have to be estimated are interstitial liquid density, the fused solid density, and the water density to interstitial liquid density ratio.

\subsection{COMPUTER MODELING CALCULATIONS}

Some mathematical modeling was performed with a finite element computer code. The computer code, EDDY-C, was originally developed at Washington State University (WSU) by Professor Lee Philipp and his associates, and has been in use since the late 1970's. The early effort was funded by the Electrical Power Research Institute (EPRI) to investigate EMI probe responses in steam generator tubes.

For the purpose of modeling much larger EMI probes for deployment in the waste tank LOWs, the EDDY-C computer code was converted and modified under the direction of Dr. Philipp (Lynch et a1. 1991, Nguyen et al. 1991, Philipp et a1. 1991).

There were a few significant results that were first confirmed by the modified EDDY-C finite element code that assisted this EMI program.

- Initial EDDY-C calculations confirmed that driver pick-up coils in a geometry comparable to a LOW would have sufficient sensitivity to detect electrical conductivity of the magnitude of tank waste contents.

- EDDY-C calculations for depth of penetration confirmed that, for low electrical conductivity medium, the depth of EMI penetration is determined by coil spacing and geometry. 
- EDDY-C calculations for coil design indicated that a large wire, wide coil would be more sensitive than a smaller wire, narrower coil, and subsequent EMI probe coils were designed in this fashion.

- The EDDY $-C$ code calculates the change of inductance in the EMI coil for a fixed current input, which is different from the actual probe measurement circuit. The actual EMI probe and electronics used for the in-tank measurements consisted of a constant voltage applied to a resonant circuit. The resonant circuit comes from the capacitance associated with the long coaxial cable and the inductance from the coil itself. The EDDY-C code utilization in modeling the EMI probe for tank moisture monitoring applications and benchmark applications is limited.

\subsection{ELECTROMAGNETIC INDUCTION HARDWARE DESCRIPTION}

The EMI hardware consists of three systems: (1) the EMI spyder and the EMI probe, (2) the eddy current testing electronics with data recorder, and (3) the EMI probe pusher components. These components are illustrated in Figure 4.1.

\subsection{ELECTROMAGNETIC INDUCTION PROBES FOR LON APPLICATIONS}

EMI probes are designed to fit inside the LOWs which are approximately $7.6 \mathrm{~cm}$ (3 in.) I.D. The EMI probe body is $7.42 \mathrm{~cm}(2.92 \mathrm{in}$.) 0. D. with small wheels extending out to $7.47 \mathrm{~cm}(2.94 \mathrm{in.}) 0.0$. The electrical coils are cylindrically wound around the outside diameter of the probe in a groove of depth $0.64 \mathrm{~cm}$ (0.25 in.).

Two EMI probes were used for measurements in the waste tanks; a 6-in. probe with four coils and a 12-in. probe with four coils. One of the four coils, the bottom one, was the energized or driving coil. The upper three coils were the receiver or pick-up coils. The three different spacings between the driving and pick-up coils achieved different depths of interrogation into the waste from the LOW with the consequent loss of vertical resolution. Different exciting frequencies also had an effect on the depth of interrogation and sensitivity of the EMI probes.

The EMI probes were guided into and centered in the LOW with custom designed EMI spyders using two pulleys. The first, large pulley makes the transition for the drive cable from horizontal to vertical while the second, small pulley positions the probe in the center of the LOW.

The EMI probes have the greatest response close to their resonance frequency. The resonant frequency depends on the number of turns in the coils on the probe (inductance) and on the length of the coaxial cable (capacitance) between the EMI probe and the MIZ-40A eddy current tester. A lumped parameter model calculation for the resonant frequency of the EMI probe with attached $25 \mathrm{~m}(83 \mathrm{ft})$ of RG-174 coaxial cable and additional cable lengths was performed with results tabulated in Table 4.1. 
WHC-SD-WM-ER-520 Rev 0

Figure 4.1. Electromagnetic Induction System.

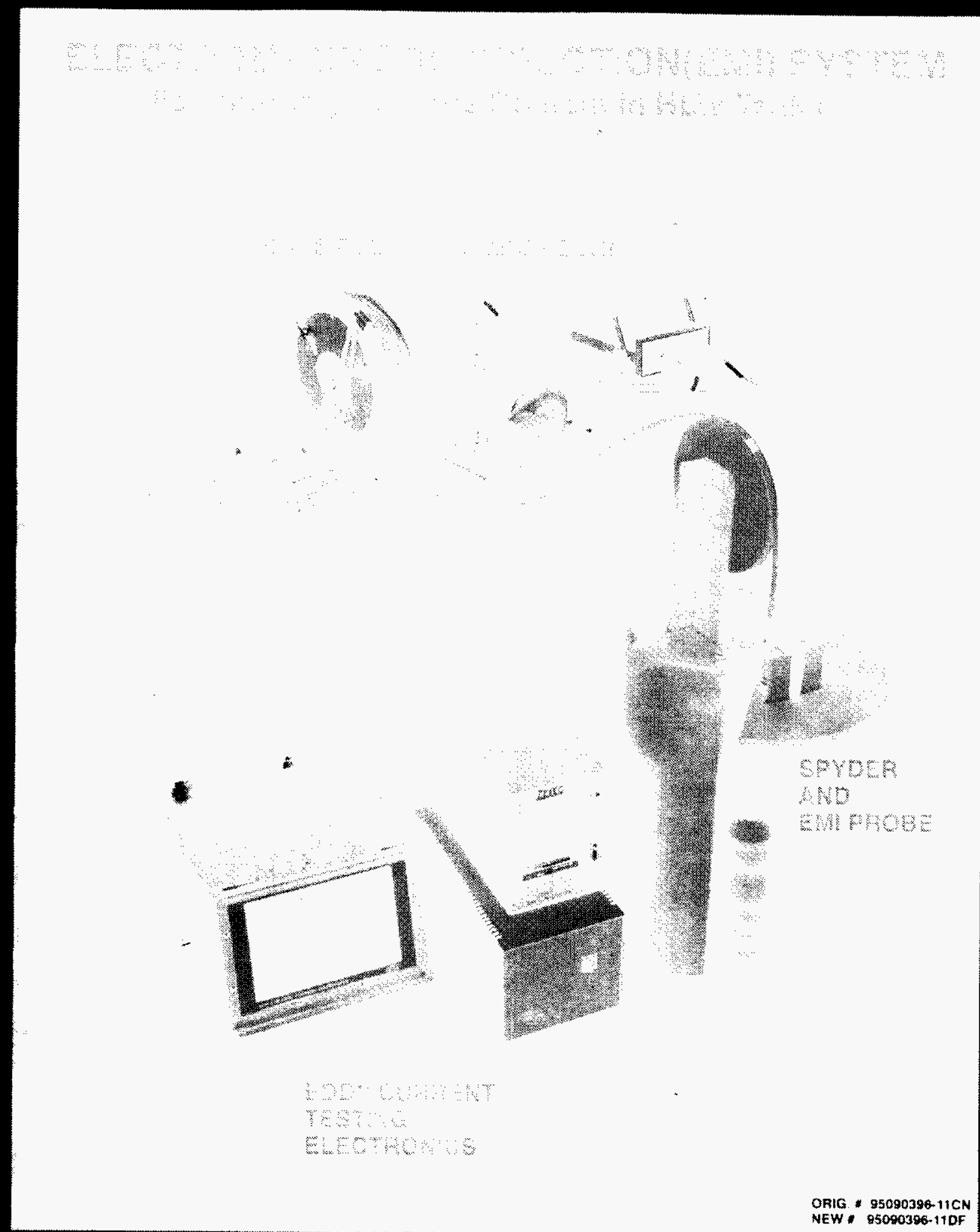




\begin{tabular}{||c|l|l||}
\hline \multicolumn{3}{|c|}{ Table 4.1 $\begin{array}{l}\text { EMI Probe Calculated Resonant Frequency } \\
\text { With Additional Coaxial Cables }\end{array}$} \\
\hline & 6 -inch Probe & 12 -inch Probe \\
\hline EMI Probe-Standard & $318.1 \mathrm{kHz}$ & $92.9 \mathrm{kHz}$ \\
\hline$+50 \mathrm{ft}$ coaxial cable & $251.3 \mathrm{kHz}$ & $73.4 \mathrm{kHz}$ \\
\hline$+100 \mathrm{ft}$ coaxial cable & $214.2 \mathrm{kHz}$ & $62.5 \mathrm{kHz}$ \\
\hline$+150 \mathrm{ft}$ coaxial cable & $189.8 \mathrm{kHz}$ & $55.4 \mathrm{kHz}$ \\
\hline$+200 \mathrm{ft}$ coaxial cable & $172.2 \mathrm{kHz}$ & $50.3 \mathrm{kHz}$ \\
\hline \hline
\end{tabular}

\subsection{MIZ-4OA EDDY CURRENT TESTER}

The MIZ-40A is an eddy current tester designed for "balance of plant" uses by ZETEC, the largest EMI company in the world serving the nuclear industry. The MIZ-4OA has a touch screen, menu driven operation that allows its use in radiation environments by an operator wearing protective clothing.

The MIZ-40A eddy current tester is basically a phase-sensitive impedance meter. It samples the signal in-phase and in-quadrature (90 out of phase) to make the measurement.

The MIZ-40A was purchased with a second analog board so that four coil input/output channels were available for use. Output \#1 is arranged for driver pick-up and accommodates the driver cojl and one pick-up coil. Output \#3 accommodates a second pick-up coil, and a specially modified output \#4 accommodates the third pick-up coil. The position indicator sends a logic pulse from the position encoder to the available output \#2 channel.

The MIZ-40A can be programmed to operate at four frequencies simultaneously from $100 \mathrm{~Hz}$ and $6 \mathrm{MHz}$. The MIZ-40A eddy current tester output is sent to a DDR-1 Data Recorder for permanent storage on a removable hard disk with subsequent transfer to analys is software on a personal computer. The MIZ-40A and the DDR-1 were connected to a power conditioner to assure a clean power supply for computer quality electronics equipment even when operating from the tank farm surveillance van generator.

\subsection{D PROBE PUSHER-PULLER FOR LON DEPLOYMENT}

The 3D probe pusher-puller is a motor and gearing that connects to an 18-in. diameter spool holding $25 \mathrm{~m}(83 \mathrm{ft})$ of $0.952 \mathrm{~cm}(3 / 8 \mathrm{in}$.) 0.D. plastic tubing containing four RG-174 coaxial cables for the EMI probe. Three auxiliary boxes connect with the 30 probe pusher-puller: the power relay enclosure (motor power supply), the drive controller joystick, and the probe position indicator display. 
This system pushes or pulls the EMI probe at a constant speed and sends logic pulses for probe position to the MIZ-40A. For deployment of the EMI probe in the tank farm LOWs, the 30 probe pusher-puller was mounted on the front bumper of a tank farm surveillance van.

The 3D probe pusher-puller has a maximum deployment speed of approximately $1 \mathrm{ft} / \mathrm{s}$. The EMI probe cable is pushed out horizontally and the custom designed EMI spyder, with two pulleys, redirects the EMI cable from horizontal to vertical and centers the cable in the LOW.

\subsection{ELECTROMAGNETIC INDUCTION ELECTRICAL CONDUCTIVITY TEST STANDS}

Electrical conductivity test stands are designed and built by PNL for laboratory tests of the EMI probe. There are two aluminum conductivity test stands and four $\mathrm{KCl}$ solution conductivity test stands. The $\mathrm{KCl}$ solution conductivity test stands have conductivities of $147.7 \mathrm{mS} / \mathrm{cm}\left(22.4{ }^{\circ} \mathrm{C}\right)$, $93.6 \mathrm{mS} / \mathrm{cm}\left(22.3^{\circ} \mathrm{C}\right), 46.5 \mathrm{mS} / \mathrm{cm}\left(21.9^{\circ} \mathrm{C}\right)$, and $15.03 \mathrm{mS} / \mathrm{cm}\left(21.6^{\circ} \mathrm{C}\right)$. These values are expected to span the range of anticipated waste tank electrical conductivities. The conductivity test stands are $46 \mathrm{~cm}$ (18 in.) high. The conductivity test stands provide known, reproducible geometries for testing EMI probe response. The test stands are illustrated in Figure 4.2.

\subsection{ELECTROMAGNETIC INDUCTION IN-TANK MEASURENENTS}

\subsection{ELECTROMAGNETIC INDUCTION SCANS IN HIGH-LEVEL WASTE TANKS}

The basic objective of the in-tank measurements was to examine the response of the EMI probe using a number of different configurations in as many tanks and tank conditions as possible. This section describes some of the results of the measurements and demonstrates the following strengths of the EMI probe.

- The EMI probe can be scanned at relatively high speeds $(0.5$ to $1 \mathrm{ft} / \mathrm{s})$ while still providing high spatial resolution.

- A single scan up a LOW interrogates the waste at multiple depths simultaneousiy.

- The EMI probe can be configured to be sensitive to small changes in the LOW and surrounding waste or be configured to "average" over a larger volume. 
WHC-SD-WM-ER-520 Rev 0

Figure 4.2. Electromagnetic Induction Laboratory Test Stands.

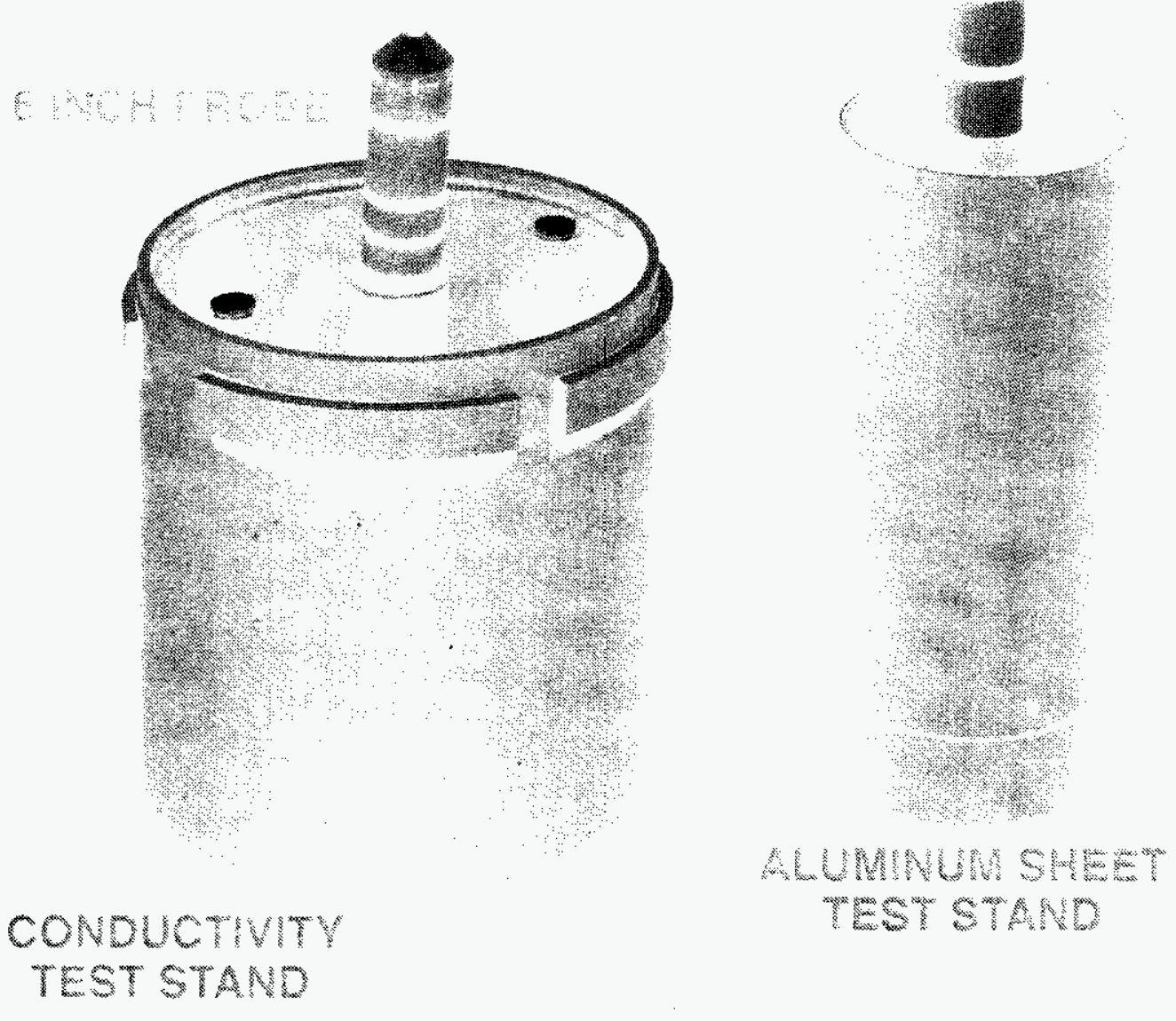

Hew

, 
Ten single-shell tanks were scanned using the EMI probe (see Table 5-1). The tanks selected included both stabilized and unstabilized tanks as well as a number of watchlist tanks. Either one or two different length EMI probes were used in an individual tank. An individual scan involved the following steps; nulling (zeroing) the probe electronics outside of the LOW, positioning the probe in the LOW using the top riser flange as a reference plane, manually running the probe down to near the bottom of the LOW, activating the data recording, and then automatically pulling the probe up the LOW. The data recording and probe pull were stopped when the probe reached the top of the LOW. The probe was then removed from the LOW and a new set of frequencies or probe was selected. The probe electronics was nulled again and the scan process repeated for that LOW. Typically, a LOW was scanned three to four times, each scan with a different probe or frequency configuration.

\begin{tabular}{|c|c|c|c|c|c|}
\hline Tank & Riser & $\begin{array}{l}\text { Probe } \\
\text { Length }\end{array}$ & $\begin{array}{c}\text { Frequency } \\
(\mathrm{kHz})\end{array}$ & $\begin{array}{c}\text { Interim } \\
\text { Stabilized }\end{array}$ & Watch 1 ist \\
\hline $241-B Y-104$ & $10 \mathrm{C}$ & 6 & $50-2000$ & yes & FECN \\
\hline \multirow{2}{*}{$241-B Y-106$} & \multirow{2}{*}{$10 \mathrm{c}$} & 6 & $50-2000$ & \multirow{2}{*}{ no } & \multirow{2}{*}{ FECN } \\
\hline & & 12 & $50-500$ & & \\
\hline $24 I-B Y-107$ & 7 & 6 & $50-2000$ & yes & FECN \\
\hline $241-B Y-111$ & 1 & 6 & $50-2000$ & yes & FECN \\
\hline \multirow{2}{*}{$241-B Y-112$} & \multirow{2}{*}{$10 a$} & 6 & $50-2000$ & \multirow{2}{*}{ yes } & \multirow{2}{*}{ FECN } \\
\hline & & 12 & $50-500$ & & \\
\hline $241-S-105$ & 14 & 6 & $50-2000$ & yes & \\
\hline $241-S-106$ & 4 & 6 & $50-2000$ & no & \\
\hline $241-T Y-103$ & 3 & 6 & $50-2000$ & yes & FECN \\
\hline \multirow{4}{*}{$241-T X-114$} & 7 & 6 & $50-2000$ & \multirow{4}{*}{ yes } & \\
\hline & \multirow{2}{*}{$9 a$} & 6 & $50-2000$ & & \\
\hline & & 12 & $50-500$ & & \\
\hline & $12 a$ & 6 & $50-2000$ & & \\
\hline $241-T X-118$ & 5 & 6 in & $50-2000$ & yes & \\
\hline
\end{tabular}

\subsubsection{Resolution and Repeatability}

Figures 5-1 and 5-2 are examples of the sensitivity and repeatability of the scans of a LOW using the EMI probe. In each figure, what looks like only two curves is actually four. A second scan was performed in the same LOW in tank 24l-BY-104 using the same probe and frequency configuration as used for a 
Figure 5.1. Repeatability of Amplitude Measurement for $241-\mathrm{BY}-104$ at $500 \mathrm{kHz}$.

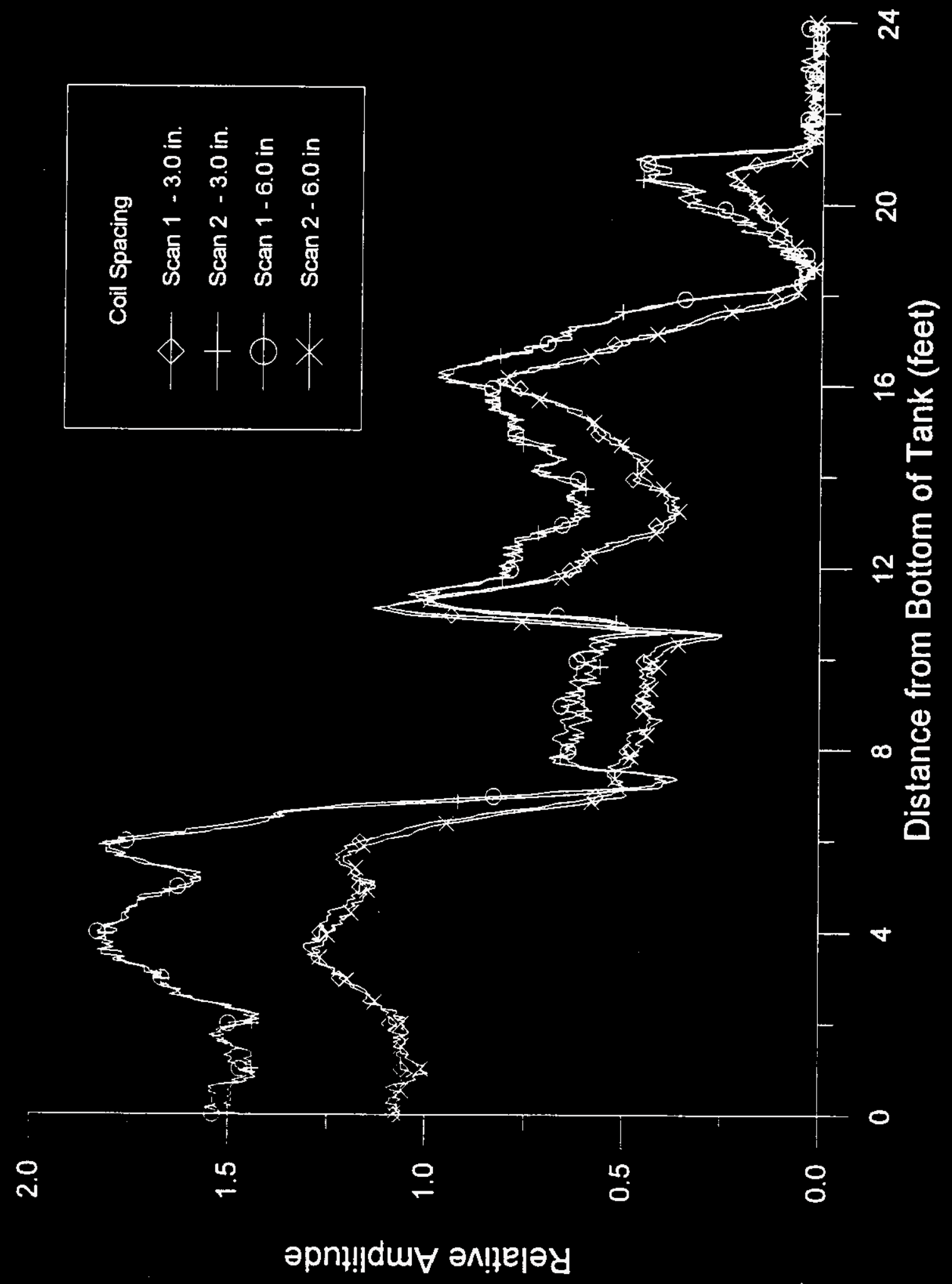


Figure 5.2. Repeatability of Phase Measurement for 241-BY-104 at $500 \mathrm{kHz}$.

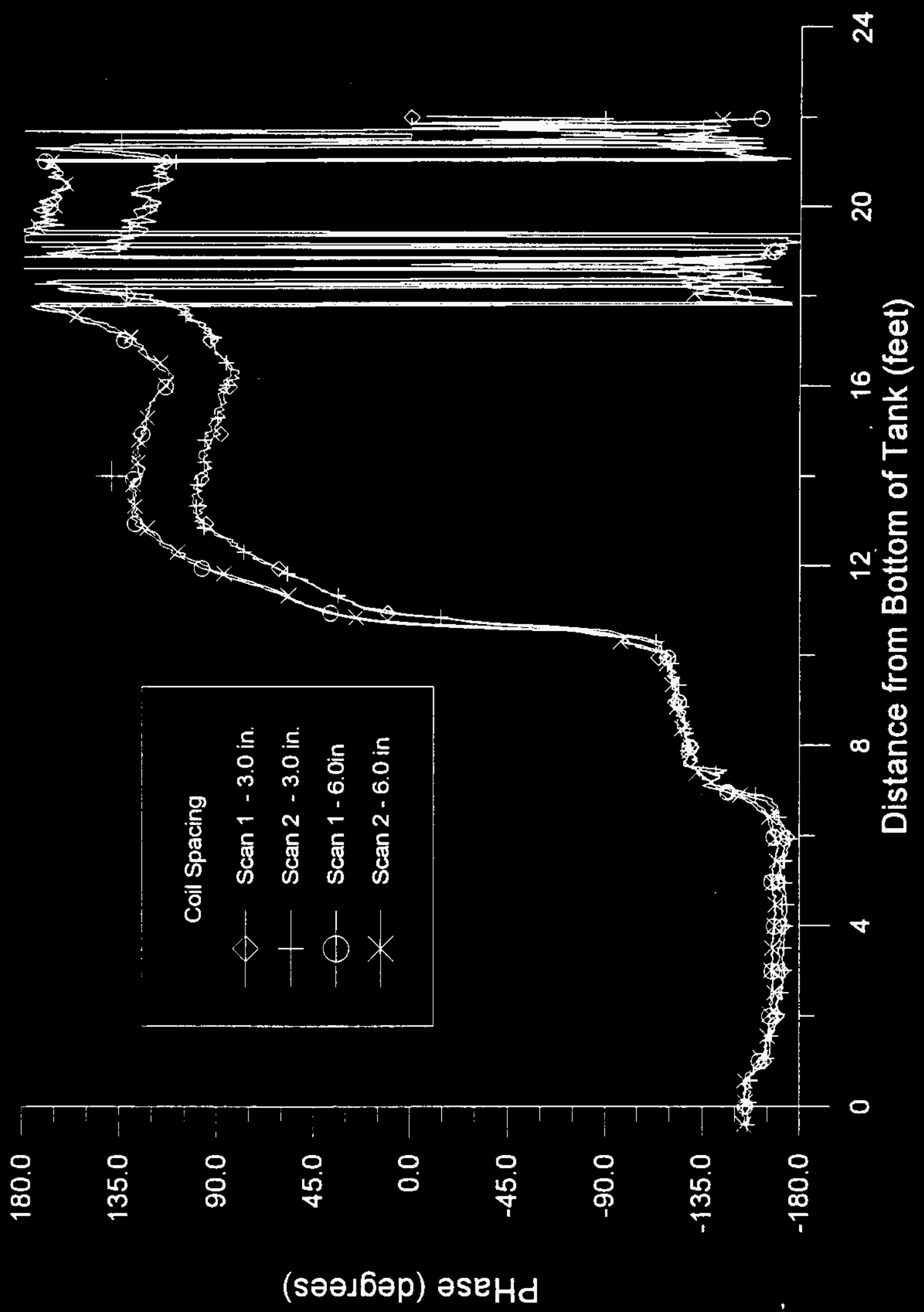


WHC-SD-WM-ER-520 Rev 0

previous scan. Two of the repeated scans are overlaid over their equivalent scans from the first measurement. The EMI probe measurement is not a statistical process requiring temporal averaging. Consequently, repeatability is excellent and resolution is a function of frequency and coil spacing, not scan speed. The repeated scans were shifted along the $x$-axis to coincide with the other pair, but the amplitudes were not changed. While the probe drive mechanism automatically pulls the probe at a constant speed, position indication is based on markers recorded only every 6 in. Consequently, the actual position of the probe is presently only known to within a few inches.

The scans in the figure show the magnitude and phase of the recorded signal for only one frequency, $500 \mathrm{kHz}$, and for two coil spacings, 3.0 and 6.0 in. Each probe consists of four coils allowing concurrent measurements of three coil pair separation distances during a single scan. The MIZ-40A eddy current tester can sample up to four frequencies simultaneously, allowing a single pull of the probe up the LOW to interrogate the waste at twelve combinations of coil spacing and frequency.

Typical probe scan velocities ranged from 0.5 to $1 \mathrm{ft} / \mathrm{s}$ for the different scans. The sample rate for a scan was also varied between 100 to 250 samples per second. Neither of these changes produced any noticeable affect on the measured scan results except the size of the data file recorded. A scan of a $45-\mathrm{ft}$ LOW has between 4,500 to 20,000 sample points, each with four frequencies and three coil positions. Oniy about one out of every 50 points is plotted in the figures. An individual feature in the scan could be expanded by this factor to increase the resolution if desired.

These figures as well as the other figures in this section have the bottom of the tank on the left side of the plot. Moving along the $x$-axis is equivaient to moving up the LOW. The relative amplitude scale in the figures is based on the digitally recorded output from the analog-to-digital convertor of the MIZ-40A eddy current tester. The amplitudes have no units but they are corrected for the amplifier gains allowing scans with different gain settings to be directly compared.

The waste in this tank, 241-BY-104, has a depth of about $12 \mathrm{ft}, 8$ to $9 \mathrm{ft}$ of sludge, and 2 to $3 \mathrm{ft}$ of saltcake. Both figures show a distinct transition at about $8 \mathrm{ft}$, which is interpreted as the boundary between the saltcake and sludge. Another transition occurs around $11 \mathrm{ft}$, which corresponds to the top of the waste. The other features above $12 \mathrm{ft}$ are explained later in the section.

\subsubsection{Interrogation Depth}

The volume of waste influencing the receiver coil signal can be adjusted by varying the frequency of the transmitted signal and the separation distance between the coils. A probe with a small coil spacing operated at a high frequency does not "see" as much of the waste as a probe with a greater coil spacing operated at a lower frequency. Figures 5.3 and 5.4 illustrate this concept for the lower frequencies, $(50$ to $500 \mathrm{kHz})$, with Figures 5.5 and 5.6 showing the higher frequencies ( 500 to $2000 \mathrm{kHz}$ ). 
WHC-SD-WM-ER-520 Rev 0

Figure 5.3. Scan Amplitude at Lower Frequencies.

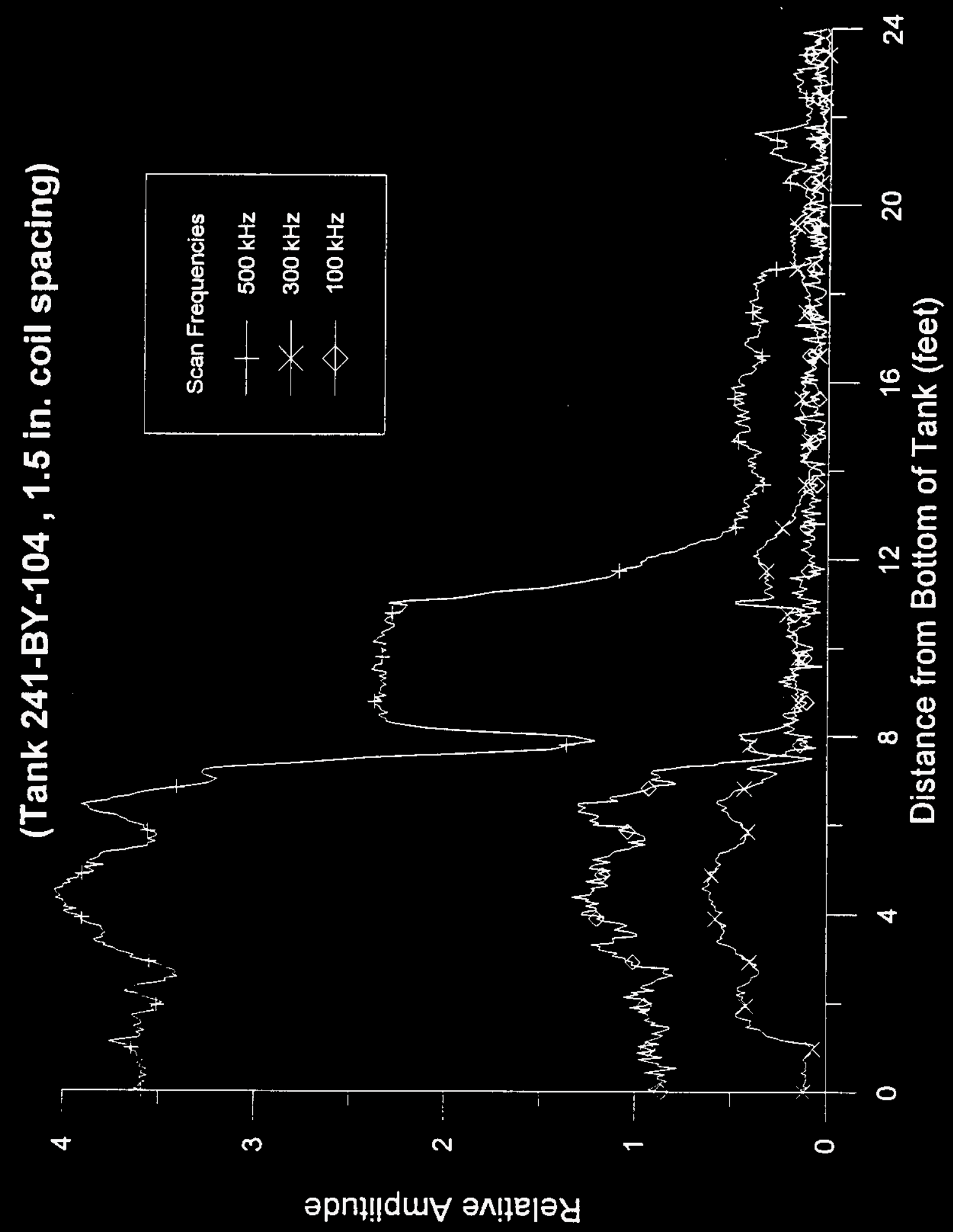


WHC-SD-WM-ER-520 Rev 0

Figure 5.4. Scan Phase at Lower Frequencies.

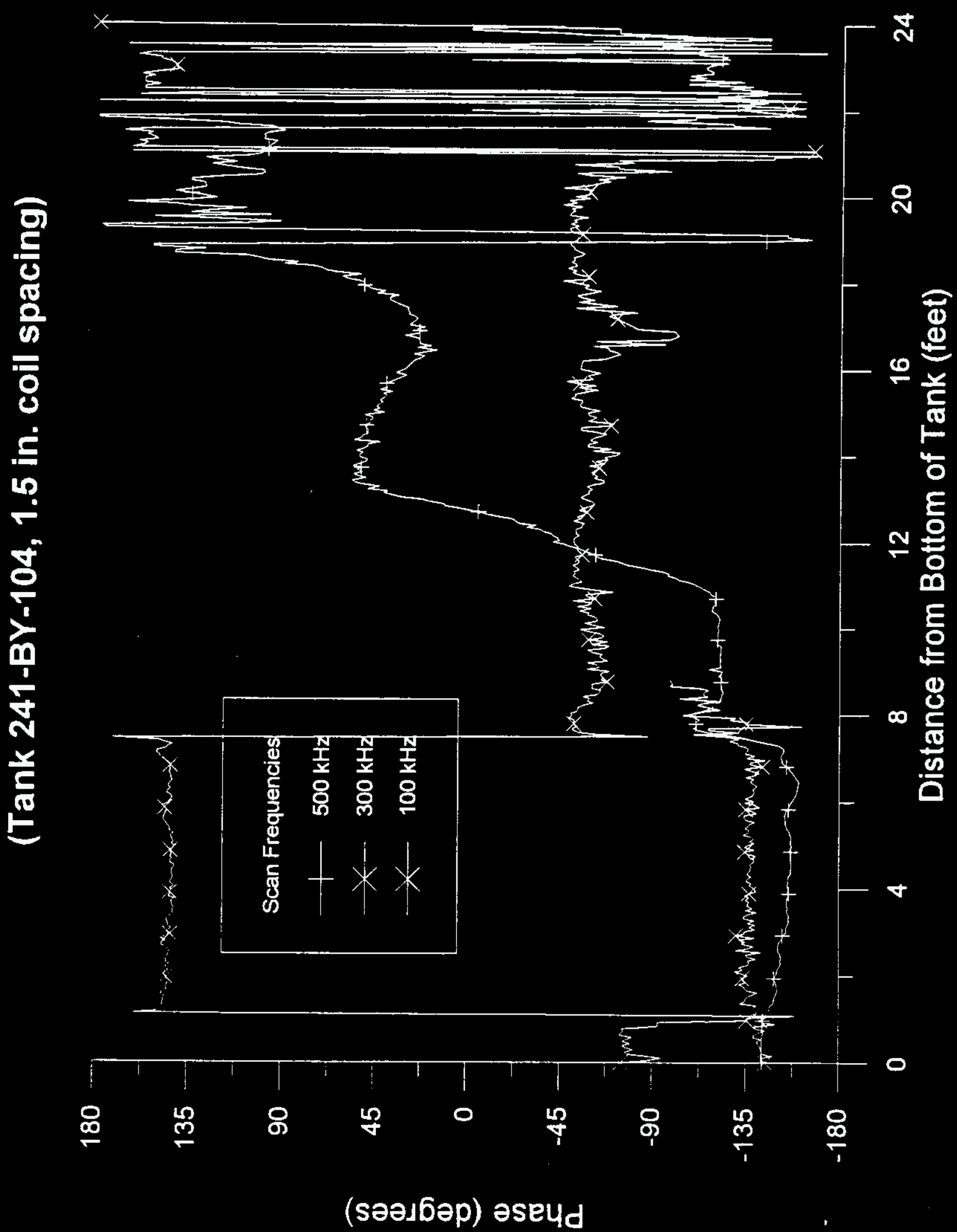




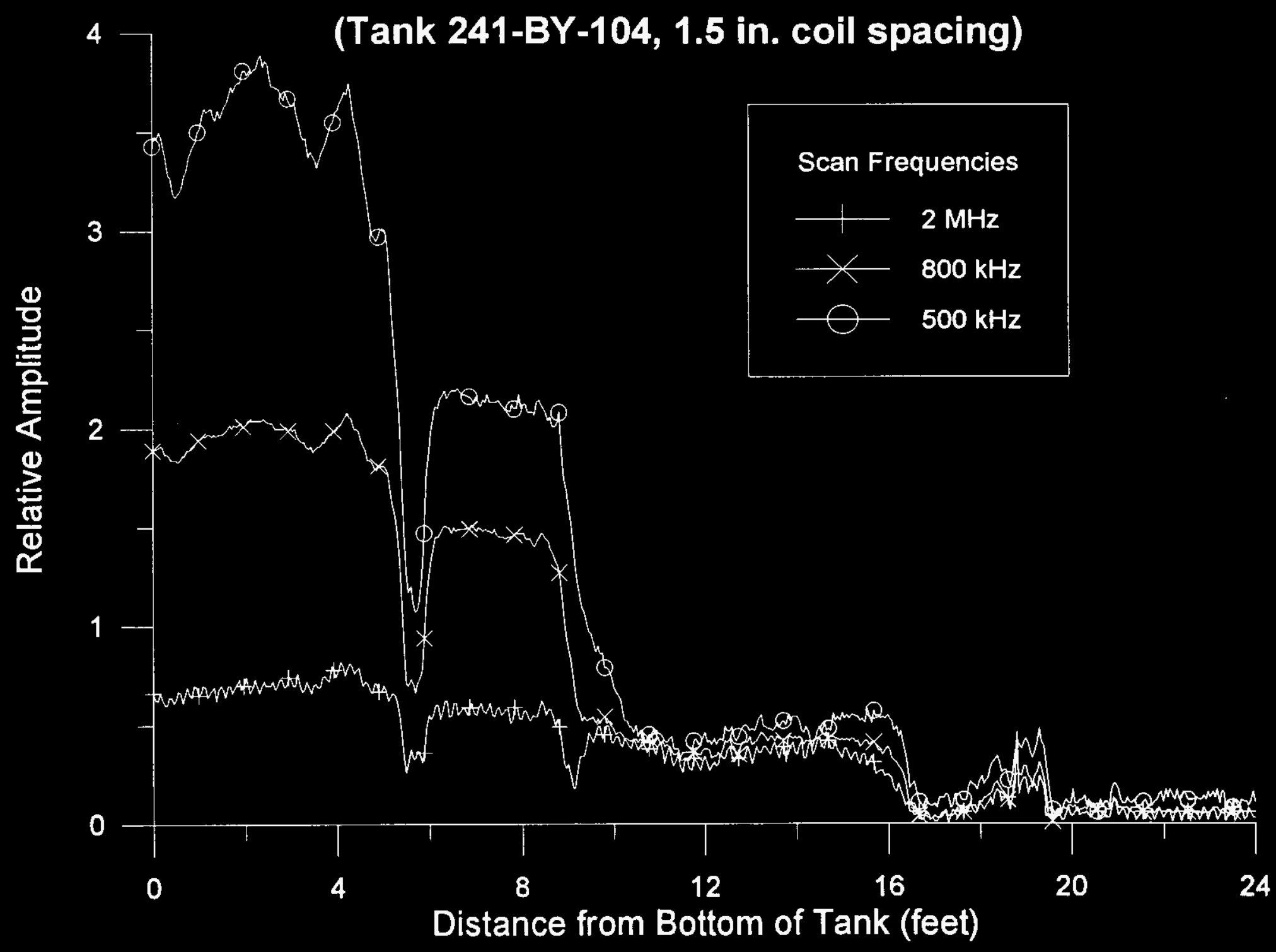

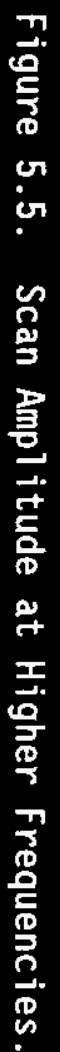

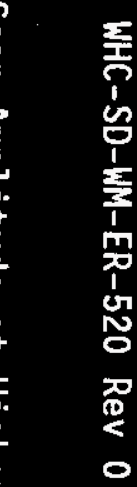


Figure 5.6. Scan Phase at Higher Frequencies.

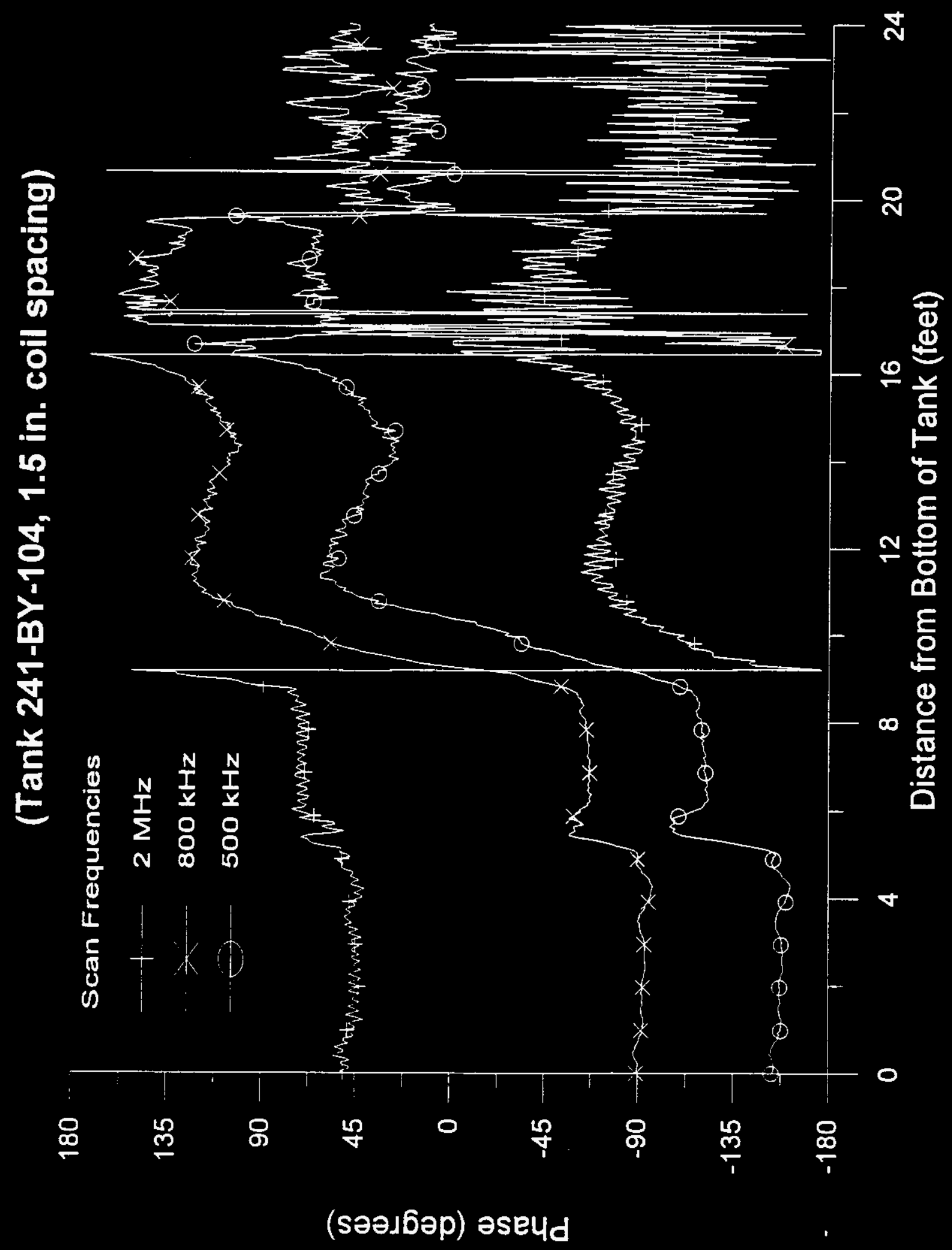


Significant amplitude variations in the scans are more prominent in the scans at the higher frequencies than at the lower frequency scans. Localized changes in material properties have a more pronounced impact on the signal at the high frequencies. The lower frequencies are less susceptible to local perturbations because their signal is being influenced by a greater volume of the waste.

Figures 5.4 and 5.6 show the phase of the received signal relative to the transmitted signal. It should be recognized that some of the most prominent vertical changes in the phase are the consequence of the nature of the inverse tangent function. As the value of the angle becomes greater than $+/-180$ degrees, an abrupt change is seen. The change from -180 degrees to -181 degree actually shows up as a 360 degree change to +179 degrees. Neglecting these abrupt transitions, the measured phase exhibits more gradual transition changes than those seen in the scan amplitude.

The coil spacing has a similar effect as changing the frequency. Small coil spacings, like the higher frequencies, tend to see more localized conditions. Similarly, the larger coil spacings view a larger region. Figures 5.7 and 5.8 demonstrate this behavior. The features seen in the 1.5-in. coil spacing scan are smoothed out in the larger coil spacing scans. Neither the amplitude not the phase scans of the 6-in. coil spacing exhibit the significant dip seen at $8 \mathrm{ft}$ from the bottom of the tank in the 1.5-in. coil scans.

\subsection{ELECTROMAGNETIC INDUCTION SCANS COMPARED TO NEUTRON AND GAMMA SCANS}

Tank 241-BY-104, as mentioned earlier, has been interim stabilized and now is estimated to contain $12 \mathrm{ft}$ of waste. Figure 5.9 shows a comparison between the neutron and EMI probe scans for this tank. Different $y$-axis scales (located on the right and left sides of the plot) were used to overlay the two scans. The sludge and saltcake regions are distinguishable in both the neutron and EMI scans. However, the EMI scan also displays additional details above $12 \mathrm{ft}$ not seen in the neutron scan. Also because of the higher spatial resolution, the saltcake plateau and dip between the saltcake and sludge region are more pronounced in the EMI scan.

Figure 5.10 shows a comparison between the same EMI scan and a gamma scan. Superimposed on the gamma scan is an estimate of the expected fall-off of the gamma count rate above the waste. A significant deviation from what is expected is seen in the region from 15 to $20 \mathrm{ft}$ in the gamma scan. This corresponds to the same behavior as the EMI probe in this region. Figure 5.11 is a photograph of the surface of the waste inside tank 241-8Y-104 in the region below the riser containing the LOW. The LOW is the right most vertical tube of the grouping of four tubes entering the waste near the center of the photograph. Also seen is a large mound of saltcake surrounding the LOW extending to several feet above the surface of the waste, probably formed before the tank was interim stabilized. This buildup on the LOW is considered to be the explanation for the features seen in both the EMI and gamma scans, but not seen in the neutron scan. 
WHC-SD-WM-ER-520 Rev 0

Figure 5.7. Scan Amplitude at Different Coil Spacings.

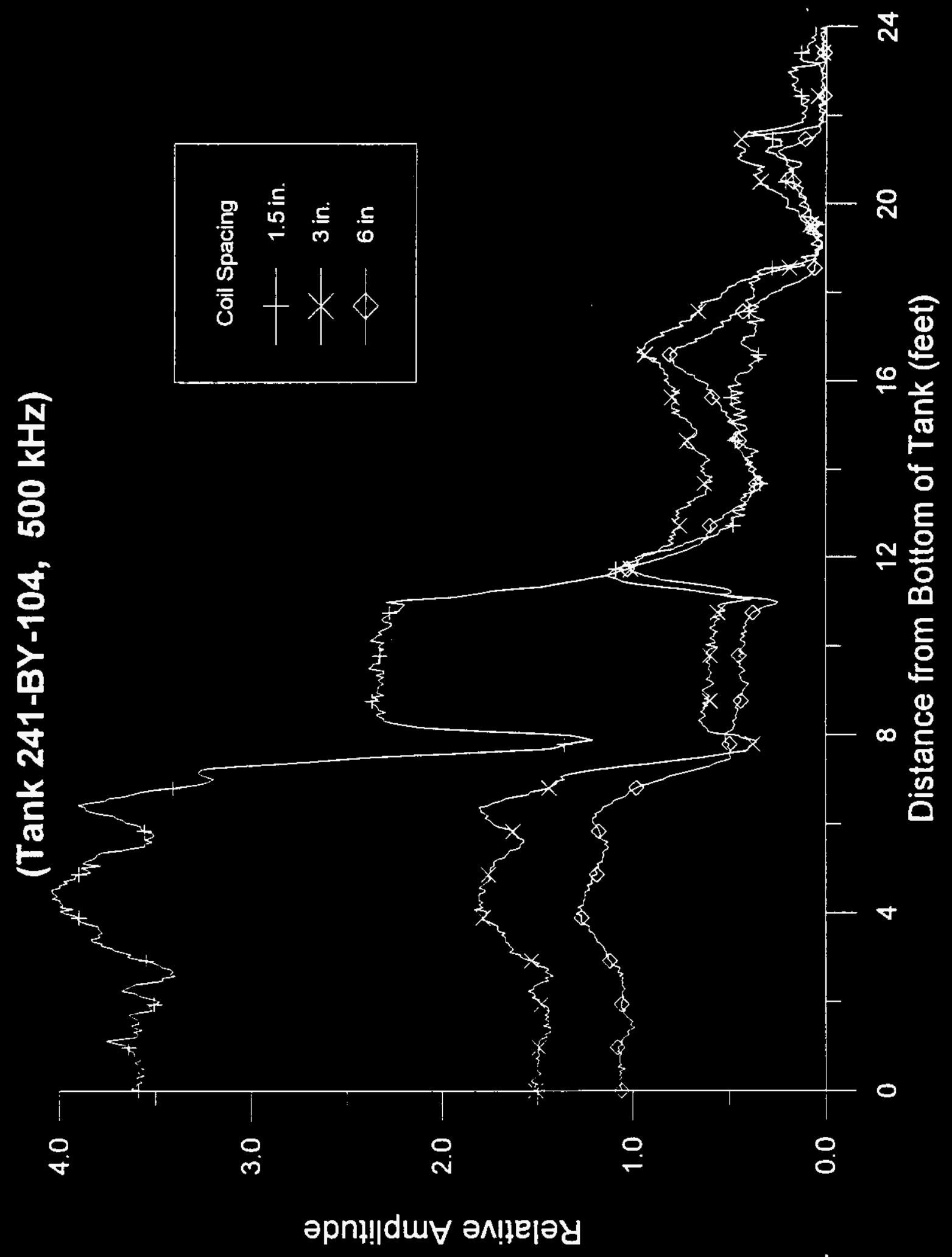


Figure 5.8. Scan Phase at Different Coil Spacings.

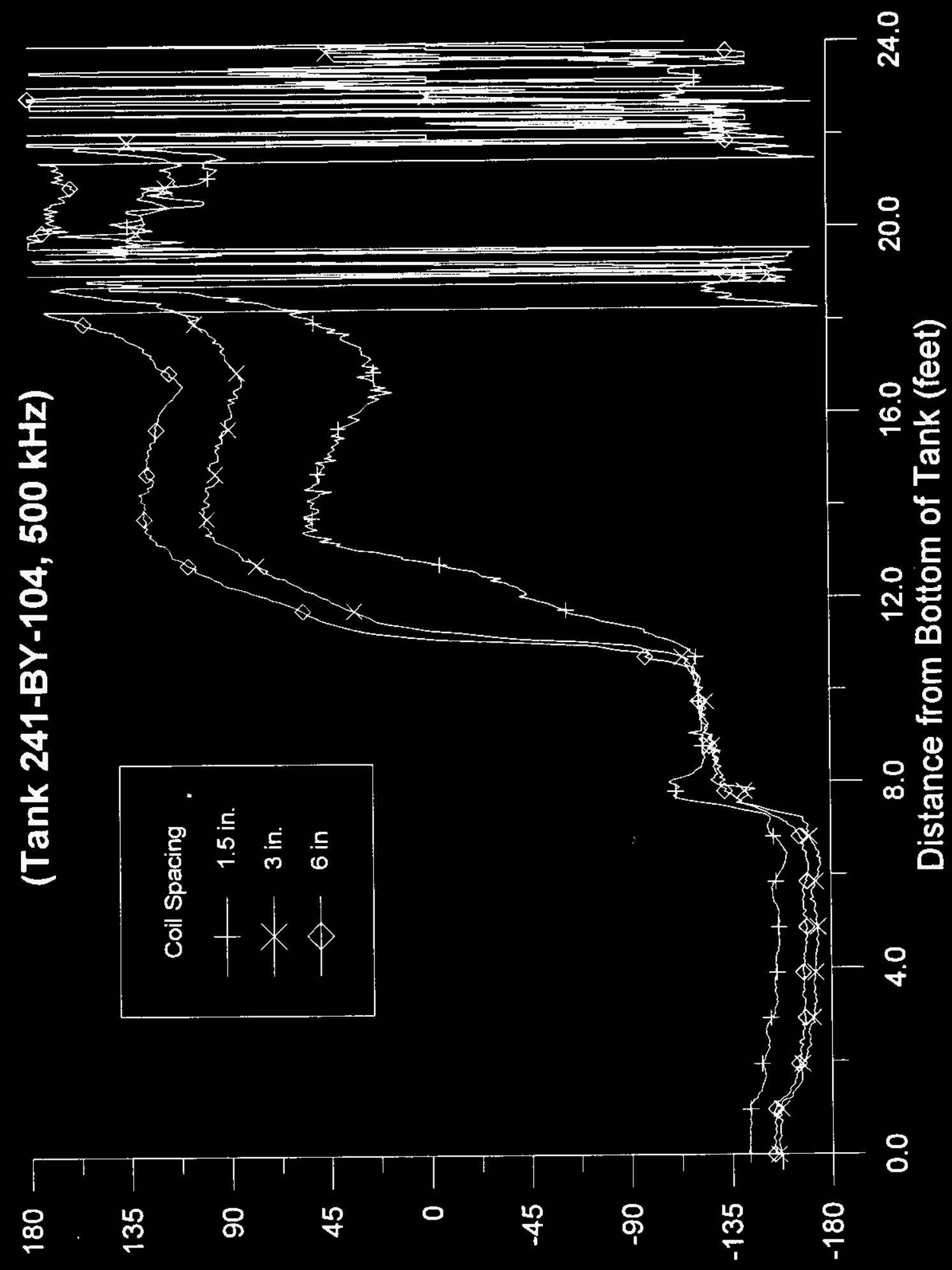

(әəљ6әр) әsечd 
Figure 5.9. Electromagnetic Induction Probe and Neutron Probe Scans.

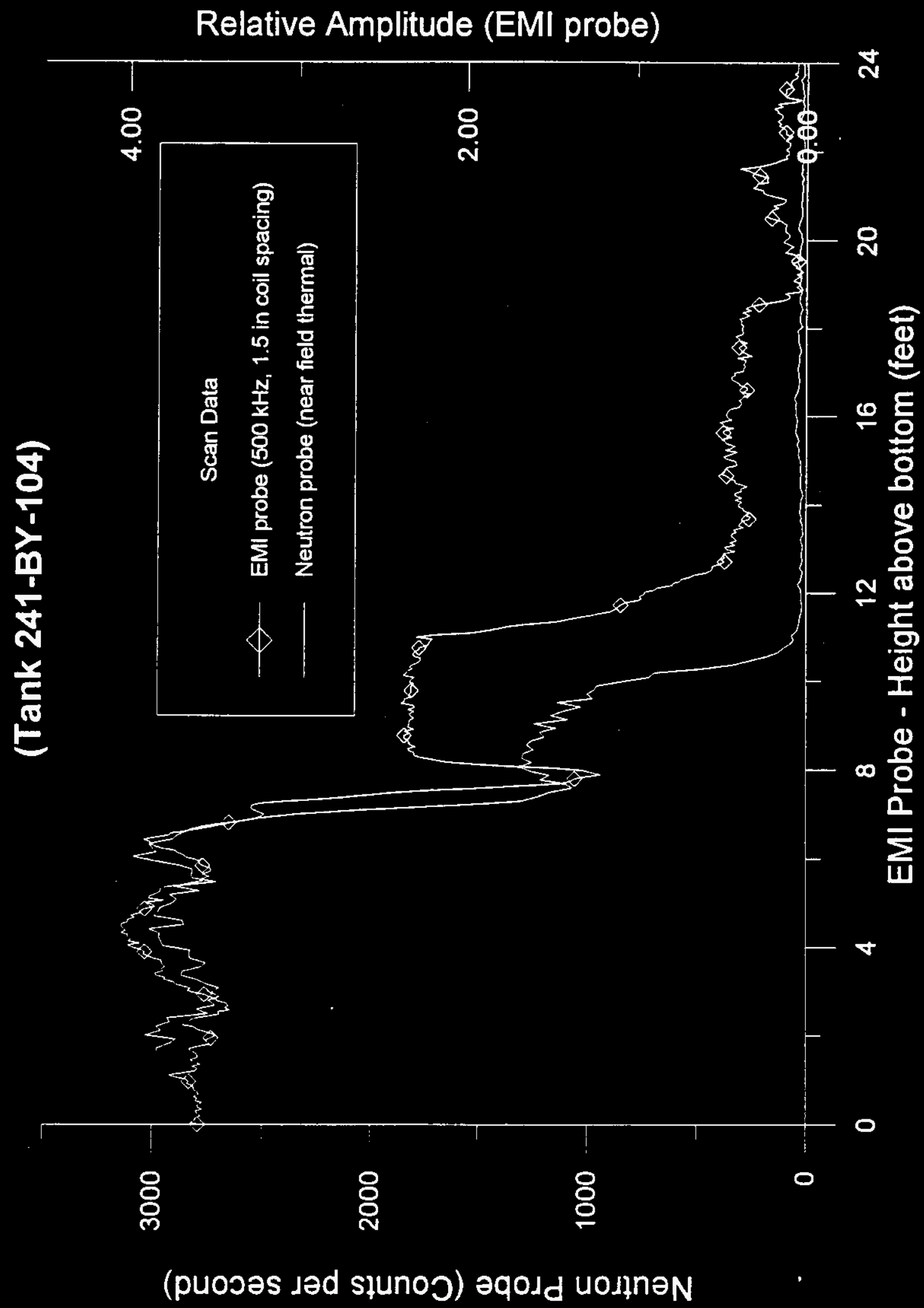


Figure 5.10. Electromagnetic Induction Probe and Gamma Probe Scans.

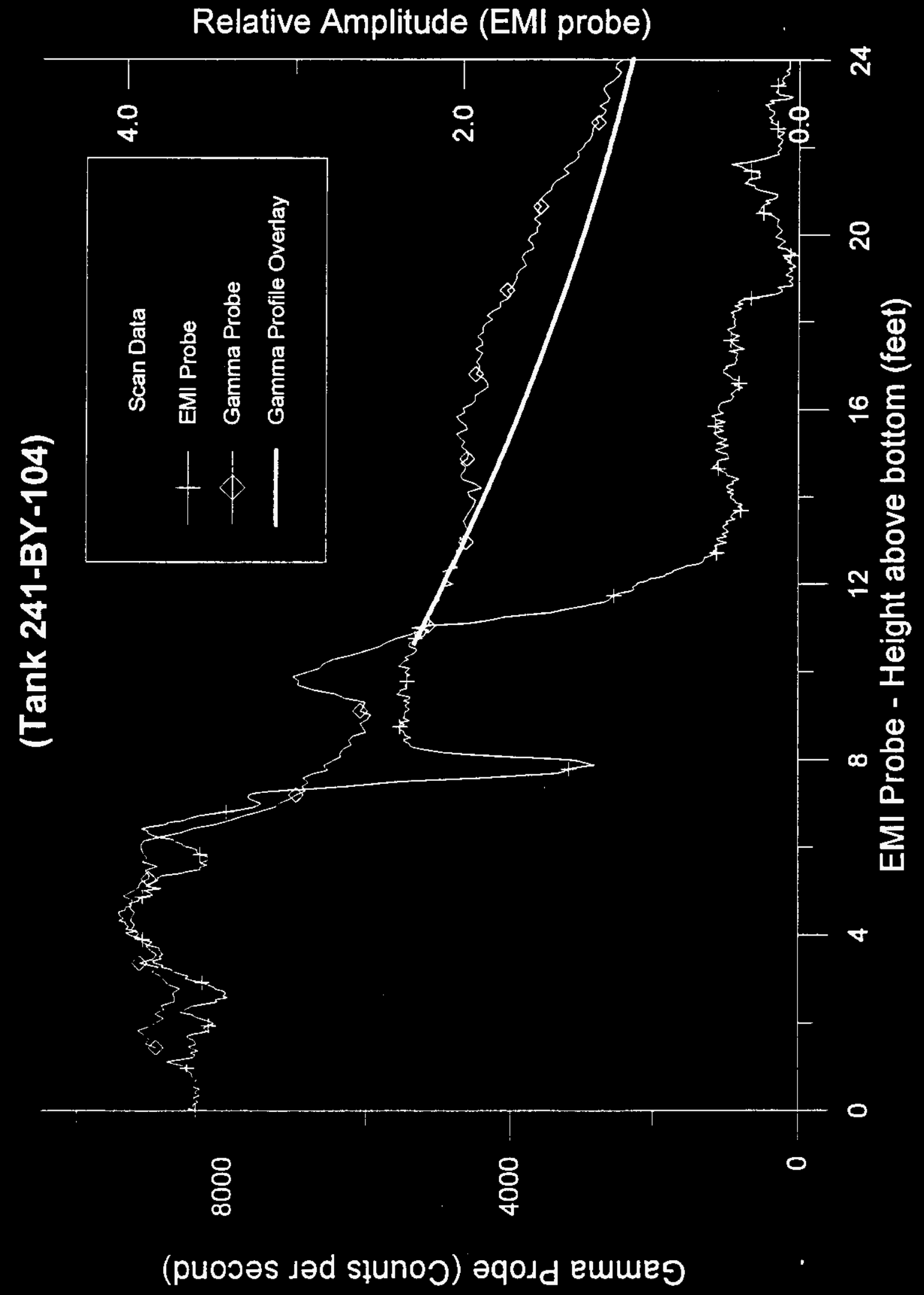


WHC-SD-WM-ER-520 Rev 0

Figure 5.11. Waste Surface inside Tank 241-BY-104.

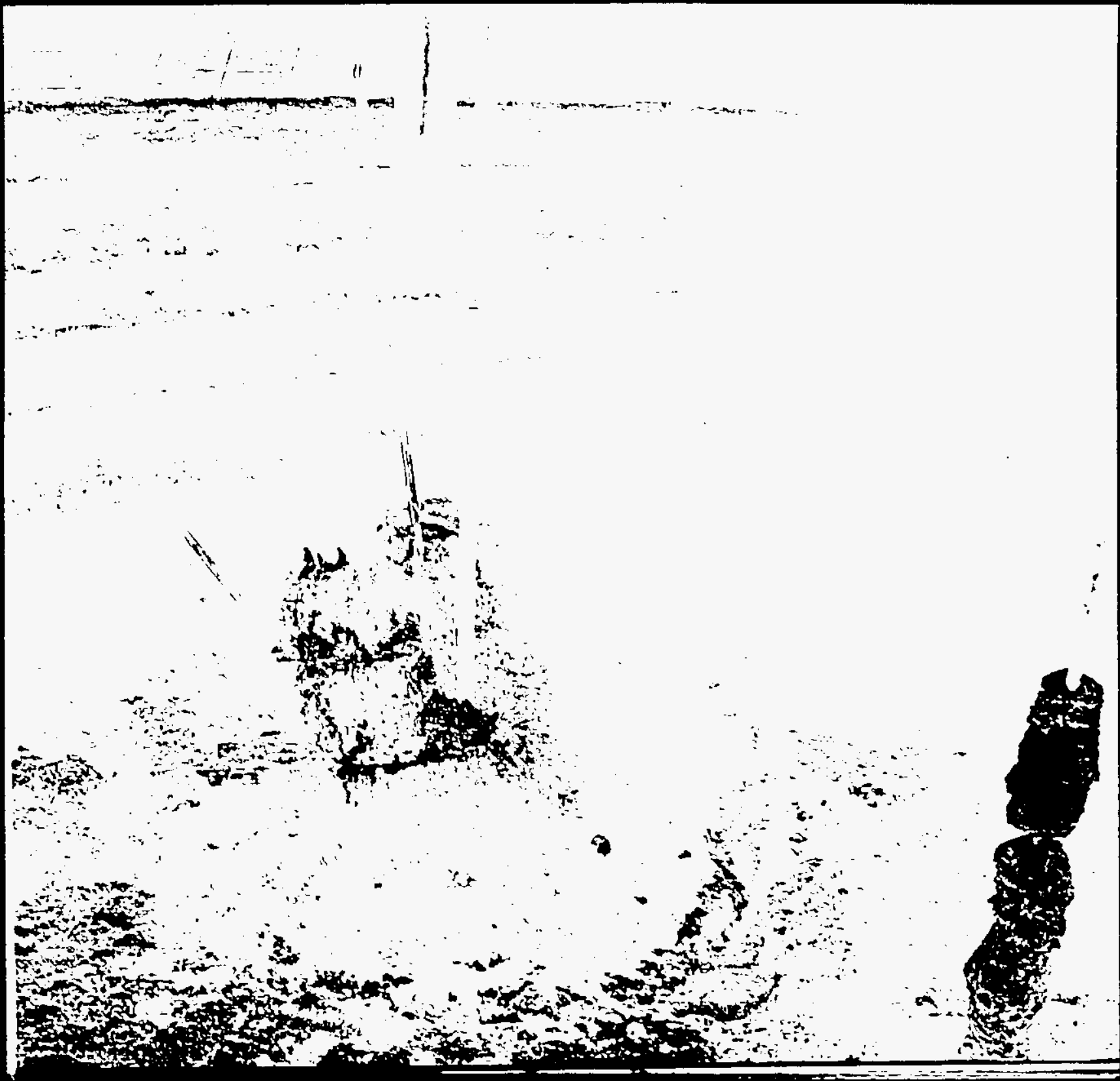

MEST COPY' AVALLABLE 
It is interesting to compare the relative amplitudes of the EMI scans at different coil spacings between the saltcake region ( 8 to $11 \mathrm{ft}$ ) and the buildup region ( 12 to $16 \mathrm{ft}$ ). Figures 5.7 and 5.8 show that the larger coil spacings are more sensitive to the buildup region. It is envisioned that the EMI scans can be used to identify the physical features surrounding the LOWs such as air gaps, water gaps, and saltcake buildup, etc., leading to a better interpretation with increased believability for both the EMI and neutron moisture measurements.

\subsection{ELECTROMAGNETIC INDUCTION SCAN CALIBRATION RESULTS}

An example of the calibration measurements using the conductivity test stands can be seen in Figure 5.12. Four of the test stands have a reference salt solutions of about $15 \mathrm{mS} / \mathrm{cm}, 50 \mathrm{mS} / \mathrm{cm}, 100 \mathrm{mS} / \mathrm{cm}$, and $157 \mathrm{mS} / \mathrm{cm}$. A fifth empty test stand containing no liquid was positioned near the other four test stands. The probe electronics was nulled (far left hand side of figure). The probe being tested was then sequentially inserted halfway into each of the test stands. The test stands were probed in order of increasing conductivity, starting with the empty test stand. The probe was raised about a foot above the test stands as it was moved from test stand to test stand during the measurements. The results for three coil spacings are shown in the figure. It is interesting to note that the signal does not return to the null level as the probe is moved from test stand to test stand. It is now surmised that the EMI probe was influenced by test stands even while a foot or more above them. All the test stand were positioned adjacent to each other. Only the higher conductivity test stand were probabiy shielded by the probe sufficiently to prevent the measurement from being influenced by the other test stands. While these measurements need to be re-run with the individual test stands isolated, they demonstrate the sensitivity of the EMI method as well as give an approximate conversion factor of $13.9 \mathrm{mS} / \mathrm{cm} / \mathrm{unit}$ measured $(157 \mathrm{mS} / \mathrm{cm}$ divided by 11.3 measured relative units).

Figure 5-13 shows a conductivity profile for tank 241-BY-104 based on this conversion constant. The electrical conductivity in the saltcake region is about $32 \mathrm{mS} / \mathrm{cm}$. Using Table 2.4, based on Archie's Law, this transiates into a liquid volume fraction of $28 \%$ to $36 \%$ for porosities from 0.4 to 0.8 .

\subsection{AREAS OF FUTURE WORK}

The following future tasks have been identified as needed for the development of moisture monitoring using the EMI probe.

Complete an analyses for all ten of the waste tanks measured with the EMI probes. The bulk of the effort up to now has been to acquire the EMI equipment and make measurements in the waste tanks. The results in this summary are based primarily on tank 241-BY-104 because of the supporting documentation available such as photographs and gamma and neutron scans. Measurements from the other nine tanks has not been examined with the same level of detail given to 241-BY-104. This work needs to be done in conjunction with the neutron probe measurements to complete the development of the EMI moisture probe. 
Figure 5.12. Calibration Measurements.

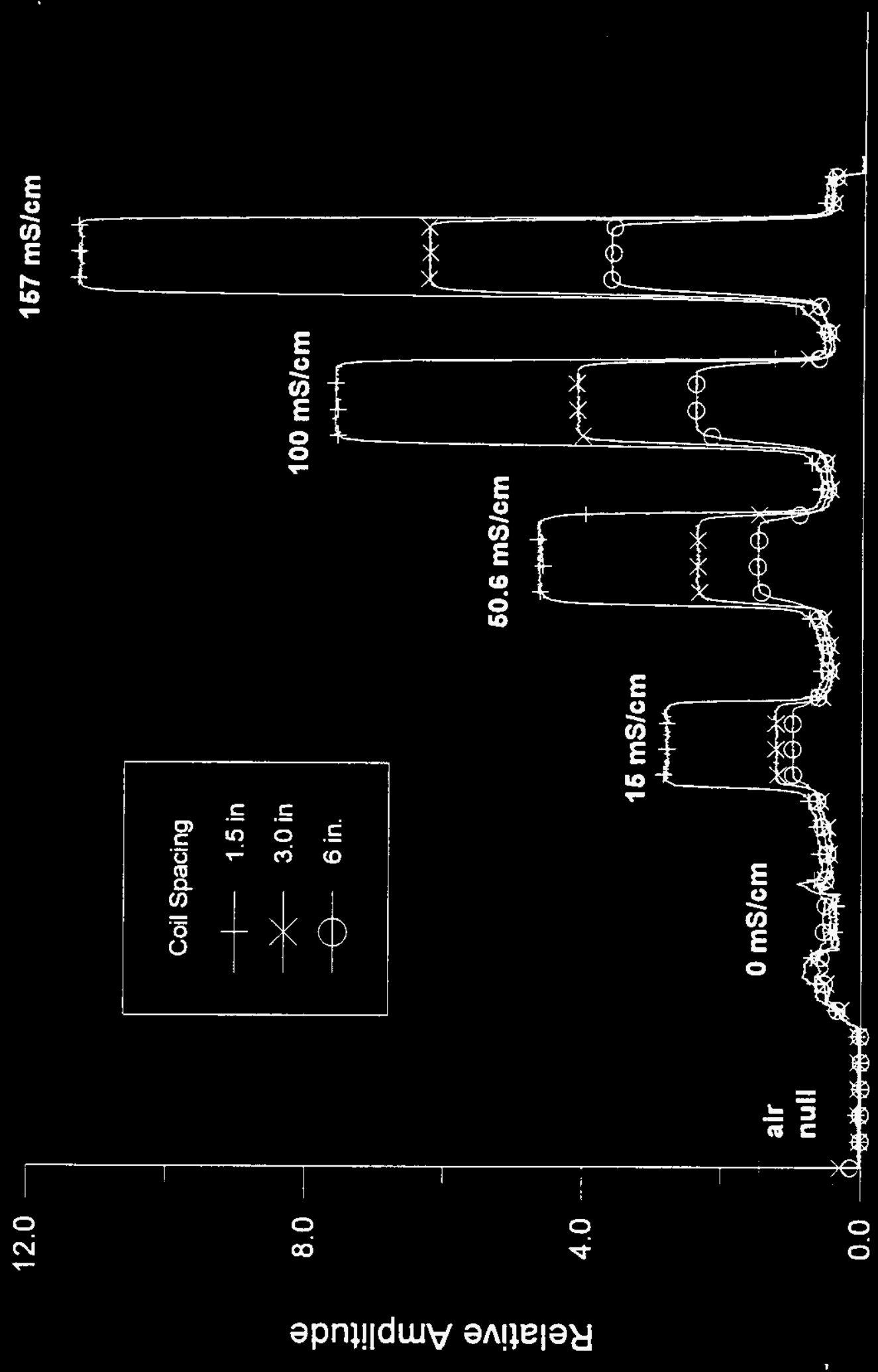


WHC-SD-WM-ER-520 Rev 0

Figure 5.13. Estimated Electrical Conductivity for Tank 241-BY-104.

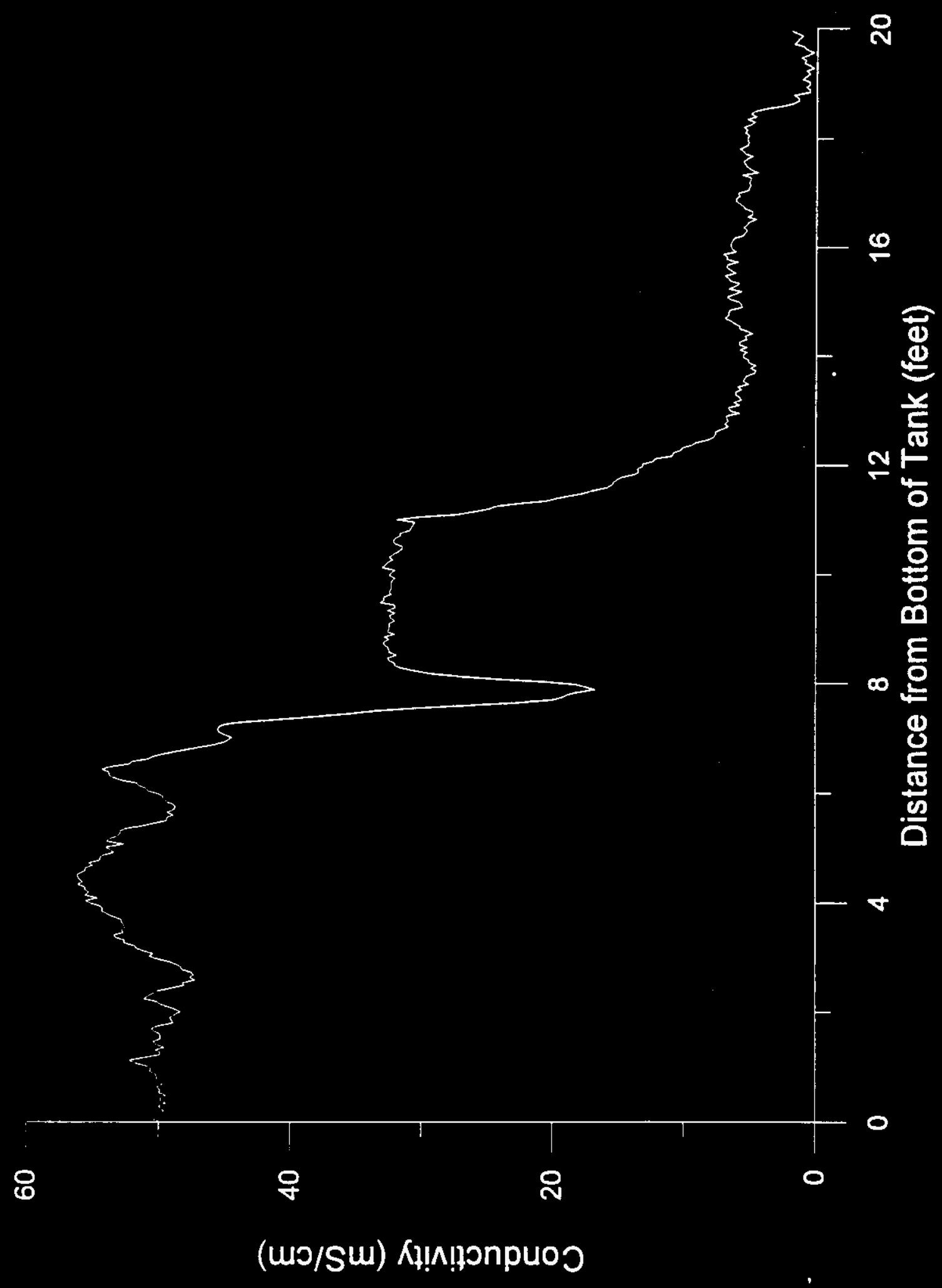


Analytic calculations of EMI probe response. Analytic calculations of the response of the EMI probe for cylindrical geometries, based on work several years ago at Oak Ridge National Laboratory (Nestor et al. 1979), has been started. These calculations are being used to identify the simulated response of the EMI probe to different physical conditions surrounding LOW, such as air or liquid gaps and saltcake buildup. This work is needed to aid in the interpretation of both the EMI and the neutron probe moisture measurements.

Routine temperature effect compensation for solution electrical conductivity temperature dependence. The temperature dependence of the liquid conductivity in the waste tanks has been investigated through a series of conductivity measurements. This work needs to be linked to the thermocouple measurements of the tank waste temperatures to correct for the temperature dependence of the electrical conductivity.

Conversion of EMI electrical conductivity measurements to volume fraction moisture content by computer method. The EMI probe measurements need to be linked with the neutron probe results. The computer code used for interpretation of the neutron measurements should be upgraded to include the EMI data. Using the EMI scans to identify the physical features surrounding the LOWs will lead to an improved moisture determination with increased believability for both the EMI and neutron measurements.

\subsection{CONCLUSIONS}

The measurement of electrical conductivity by the EMI technique is an established method used for well-logging in the geophysical community since the 1940's. Standard relationships have been developed, such as Archie's Law, to relate moist solid electrical conductivity to the conductivity of the interstitial liquid, the porosity of the solid, and the liquid volume fraction occupied.

The electrical conductivity of the contents of a typical single-shell waste tank was defined in a series of experiments with different mixtures of chemicals to determine the electrical conductivity contribution from $\mathrm{NaNO}_{3}$, $\mathrm{NaNO}_{2}, \mathrm{NaOH}$, and $\mathrm{NaAlO}_{2}$. One advantage of the EMI probe is that at moisture contents below the hydraulic conductivity limit, the EMI probe will measure near zero electrical conductivity. The hydraulic conductivity limit depends on porosity of the solid, but occurs about 0.08 to 0.12 volume fraction of liquid in the solid.

EMI hardware has been acquired. Laboratory tests were performed that demonstrate the increase in EMI response with electrical conductivity in the test stand medium. The EMI technique has been employed in the tank farms to scan ten HLW tanks and the results were compared to the neutron probe, the gamma probe, and to other EMI scans performed at different frequencies or different coil spacings. 
WHC-SD-WM-ER-520 Rev 0

Established characteristics of the EMI probe are:

- High vertical spatial resolution dependent on EMI coil spacing,

- High radial spatial resolution dependent on EMI coil spacing with multiple depth interrogations possible in a singie scan,

- Ability to look through adjacent regions to deeper regions,

- Sensitive to small changes in material properties,

- Light weight, low power probes,

- Very sensitive to loss of hydraulic conductivity which occurs about 0.08 to 0.12 volume fraction of liquid, depending on porosity.

\subsection{REFERENCES}

Barney, G. S., 1976, Vapor-Liquid-Solid Phase Equilibria of Radioactive Sodium Salt Wastes at Hanford, ARH-ST-133, Atlantic Richfield Hanford Company, Richl and, Washington.

de Witte, L., 1953, Relations Between Resistivities and Fluid Contents, The 0il and Gas Journal, P 120.

Do11, H. G. 1949, "Introduction to Induction logging and Application to Logging of Wells Drilled with 0il Base Mud," Journal of Petroleum Technology, v. 1, pp 148-162.

Lynch, D. J., A. Mahmood, L. D. PhiTipp, and Q. H. Nguyen, 1991, A Normalization Scheme for Comparing Eddy Current Differential Probe Signals Using a Finite Element Formulation, Research in Non-Destructive Evaluation 3:221-234.

Moran, H. H. and K. S. Kunz, 1962, "Basic Theory of Induction Logging and Application to Study of Two-Coil Sondes," Geophysics, v. XXVII, pp 829858.

Nestor, C. W., Jr., C. V. Dodd, and W. E. Deeds, 1979, Analysis and Computer Programs for Eddy Current Coils Concentric with Multiple Cylindrical Conductors, ORNL-5220, Oak Ridge National Laboratory, Oak Ridge, Tennessee.

Nguyen, Q. H., L. D. Philipp, D. J. Lynch; and A. Mahmood, 1991, Modeling the Differential Eddy Current Probe for Steam Generator Tubing Inspections Using 2 Parameters, NE-Vol. 6, NDE Techniques for Nuclear Heat Exchangers $p$ 1-7.

Philipp, L. D., Q. H. Nguyen, D. D. Derkacht, D. J. Lynch, and A. Mahmood, 1991, Exact First Order Finite Element Modeling for Eddy Current NDE, Research in Non-Destructive Evaluation 3:235-253. 
Reynolds, D. A., D. L. Herting, 1984, Solubilities of Sodium Nitrate, Sodium Nitrite, and Sodium Aluminate in Simulated Nuclear Waste, RHO-RE-ST-12 P, Rockwell Hanford Operations, Richland, Washington.

Serra, 0., 1984, Fundamentals of We7l-Log Interpretation, Elsevier Publishing Company.

Van Vleet, R. J., 1993, Radionuclide and Chemical Inventories for the SingleShell Tanks, WHC-SD-WM-TI-565, Westinghouse Hanford Company, Richland, Washington.

Wait, J. R., 1971, Electromagnetic Probing in Geophysics, The Golem Press, Boulder, Colorado. 